\title{
Biomarker-driven management strategies for peripheral T cell lymphoma
}

Erin Mulvey and Jia Ruan*

\begin{abstract}
Peripheral T cell lymphomas are heterogeneous diseases which remain treatment challenges. Recent advances in molecular and genomic profiling have provided unprecedented insight into disease pathogenesis driven by distinct cells of origins and molecular pathways. The discovery and clinical application of molecular biomarkers in PTCL subtypes has the potential to transform personalized care for patients with PTCL in diagnosis, prognosis, and therapy. Targeting CD30+ PTCL with the antibody-drug conjugate brentuximab vedotin in the relapsed setting and in combination with chemotherapy in the frontline setting has improved patient survivals. Epigenetic modifying agents, including HDAC inhibitors and hypomethylating agents, have demonstrated broad clinical efficacy and durability and are in clinical development for combination strategies for both relapsed and frontline settings. Wideranging novel agents targeting critical intracellular pathways and tumor microenvironment are in active exploration to define clinical activities. This review summarizes PTCL-specific biomarkers which are increasingly incorporated in clinical practice to guide precision diagnosis and personalized treatment.
\end{abstract}

Keywords: CD30-positive peripheral T cell lymphoma (PTCL), Nodal PTCL with T follicular helper (TFH) phenotype, Epigenetic targeting, HDAC inhibitors, Hypomethylating agents, Tumor microenvironment

\section{Introduction}

Peripheral $\mathrm{T}$ cell lymphomas (PTCL) are a heterogeneous group of non-Hodgkin lymphomas (NHL) derived from mature T/NK cells, encompassing $5-10 \%$ NHL in Western countries with a higher incidence of $15-20 \%$ in Asia and South America [1, 2]. Despite divergent cells of origin and mechanisms of lymphomagenesis, management of PTCL has historically followed the treatment framework for aggressive B cell NHL, in part due to lack of understanding of subtype-specific disease pathogenesis, as well as difficulty of conducting dedicated prospective treatment studies. Although generally not curative with the exception of ALK+ ALCL, cyclophosphamide, doxorubicin, vincristine, prednisone (CHOP) is the most commonly prescribed initial treatment for systemic PTCL. While autologous stem cell transplant may

\footnotetext{
* Correspondence: jruan@med.cornell.edu

Meyer Cancer Center, Weill Cornell Medicine, 1305 York Avenue, 7th Floor, New York, NY 10021, USA
}

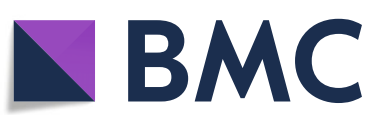

extend progression-free survival (PFS) for some patients, relapse remains common. Recent advances in the molecular and genetic bases of PTCL biology, as well as emergence of targeted therapeutic agents, have made it possible to envision personalized therapeutic progress.

\section{Biomarker-driven classification of PTCL}

There are over 30 different subtypes of peripheral $\mathrm{T}$ cell lymphoma in the 2016 WHO classification of lymphoid malignancies. The most prevalent nodal $\mathrm{T}$ cell lymphomas are peripheral $\mathrm{T}$ cell lymphoma, not otherwise specified (PTCL-NOS); nodal T cell lymphoma with $\mathrm{T}$ follicular helper (TFH) phenotype which includes angioimmunoblastic T cell lymphoma (AITL); and systemic anaplastic large cell lymphoma (sALCL). Less common subtypes include extranodal NK/T cell lymphoma, nasal type (ENKTL), adult $\mathrm{T}$ cell lymphoma/ leukemia (ATLL), enteropathy-associated $\mathrm{T}$ cell lymphoma (EATL), hepatosplenic T cell lymphoma (HSTL),

(c) The Author(s). 2020 Open Access This article is licensed under a Creative Commons Attribution 4.0 International License, which permits use, sharing, adaptation, distribution and reproduction in any medium or format, as long as you give appropriate credit to the original author(s) and the source, provide a link to the Creative Commons licence, and indicate if changes were made. The images or other third party material in this article are included in the article's Creative Commons licence, unless indicated otherwise in a credit line to the material. If material is not included in the article's Creative Commons licence and your intended use is not permitted by statutory regulation or exceeds the permitted use, you will need to obtain permission directly from the copyright holder. To view a copy of this licence, visit http://creativecommons.org/licenses/by/4.0/. The Creative Commons Public Domain Dedication waiver (http://creativecommons.org/publicdomain/zero/1.0/) applies to the data made available in this article, unless otherwise stated in a credit line to the data. 
and subcutaneous panniculitis-like $\mathrm{T}$ cell lymphoma (SPTL), amongst others. The complexity of PTCL reflects divergent cells of origin and mechanisms of lymphomagenesis.

\section{PTCL, not otherwise specified (NOS)}

PTCL, NOS is the most common subtype of PTCL, accounting for approximately $30 \%$ of PTCL in Western countries and approximately $20-25 \%$ in Asia [1]. There is no characteristic immunophenotype for PTCL, NOS. $\mathrm{T}$ cell-associated antigens such as CD2, CD3, CD5, and CD7 are variably expressed; one or more antigens such as CD5 or CD7 are frequently lost. Tumor cells can express either $\mathrm{CD} 4$ or $\mathrm{CD} 8$, with the majority expressing CD4. Clonal $\mathrm{T}$ cell receptor (TCR) gene rearrangements are usually detected and mostly show alpha/beta $\mathrm{T}$ cell receptors (TCR beta positive). Gene expression profiles (GEPs) have identified two subgroups of PTCL, NOS, with distinct gene expression driven by the transcription factors TBX-21 or GATA-3, which promote differentiation of CD4+ T cells into TH1 and TH2 helper cells, respectively. The GATA3 subgroup was significantly associated with poor survival outcome $[3,4]$.

\section{Systemic anaplastic large cell lymphoma}

Systemic anaplastic large cell lymphoma (sALCL) is the second most common PTCL subtype and accounts for $24 \%$ of PTCL in the USA, with less incidence in Europe and Asia $[2,5]$. There are three distinct forms of sALCL, including ALK-positive ALCL which has a peak incidence in children and young adults and is associated with translocations involving ALK gene located on chromosome 2p23, ALK-negative ALCL that typically presents in older adults, and the breast implantassociated ALK-negative sALCL. The immunophenotype of ALCL is notable for universal expression of CD30, frequent expression of TIA1, granzyme $B$, perforin, EMA, and low expression of CD8 and CD56. The majority of ALCL have clonally rearranged TCR genes, while roughly $10 \%$ in the null group have no rearrangement of TCR. Cytogenetic studies play a key role in ALCL diagnosis. ALK-positive ALCL most frequently has $t(2 ; 5)$ which fuses nucleophosmin (NPM) gene on chromosome $5 \mathrm{q} 35$ with the ALK gene on chromosome $2 \mathrm{p} 23$. NPM-ALK is an oncogenic tyrosine kinase which promotes signaling of JAK/STAT pathway. Less frequent variant $A L K$ rearrangements include $\mathrm{t}(1 ; 2)$ and $\mathrm{t}(2 ; 3)$. In ALK-negative ALCL, recurrent chromosomal rearrangements involving the DUSP22-IRF4 locus on 6p25.3 were associated with favorable outcomes, while those involving TP53 homolog TP63 on 3q28 were associated with aggressive clinical behavior and poor outcomes [6]. Gene expression signatures of ALCL showed hyper-activation of STAT3 due to rearrangements of ALK tyrosine kinase or activating mutations in the JAK/STAT pathway.

\section{Nodal PTCL with T follicular helper phenotype}

The 2016 WHO revision brings together T cell lymphoma subtypes including angioimmunoblastic $\mathrm{T}$ cell lymphoma, follicular $\mathrm{T}$ cell lymphoma (FTCL), and PTCL with $T$ follicular phenotype under the provisional entity of nodal PTCL with TFH phenotype, which shared TFH-related antigens and recurrent genetic abnormalities. AITL is one of the more common PTCLs encountered in Western countries, accounting for $\sim 28 \%$ PTCL in Europe, with lower incidence in North America and Asia $(\sim 15 \%)$ [7]. Patients typically present with advanced-stage disease and symptoms of a systemic illness such as rash, fever, and malaise. AITL can also manifest with immunologic abnormalities such as polyclonal hypergammaglobulinemia or autoimmune cytopenias. The histology of AITL is characterized by a polymorphous infiltrate of immune cells with a prominent proliferation of high endothelial venules. The tumor cells express follicular $\mathrm{T}$ helper cell markers including CD10, CXCL13, PD-1, BCL6, and ICOS. Molecular studies show that $\mathrm{T}$ cell receptor genes are rearranged in 75 to $90 \%$ of cases, while immunoglobulin heavy chains may be rearranged in up to $25 \%$ due to expansion of Epstein-Barr virus (EBV)-associated immunoblastic B cell clones. Gene expression profiling demonstrates a molecular signature typical of follicular helper $\mathrm{T}$ cell origin $[8,9]$, with recurrent driver mutations in TET2, $I D H 2, D N M T 3 A$, and $R H O A$, which are implicated in epigenetic regulation.

\section{Extranodal natural killer/T cell lymphoma, nasal type}

ENKTL is most common in Asia and South America, where EBV infection is endemic. Virtually, all cases contain EBV-encoded small nuclear RNAs (EBERS) [2, 10]. Clinical presentation is notable for mid-facial extranodal lymphoma associated with vascular invasion and necrosis. The immunophenotype of ENKTL is similar to that of natural killer cells which express CD2, CD56, and cytotoxic granule proteins such as granzyme B, TIA-1, and perforin, and lack surface $T$ cell receptor (TCR). There is no typical diagnostic cytogenetic change in ENKTL.

\section{Adult T cell leukemia-lymphoma}

ATLL is a peripheral T cell lymphoma subtype associated with infection by human $\mathrm{T}$ cell lymphotropic virus type 1 (HTLV-1) of CD4 cells in endemic areas such as southern Japan and the Caribbean basin [11]. The long-term risk of developing ATLL following HTLV-I infection has been estimated to be 4 to $5 \%$, usually after a latency period of several decades. 
Several clinical variants of ATLL have been described, including acute, lymphomatous, chronic, and smoldering. Peripheral blood smears from leukemia patients exhibit bizarre hyperlobated nuclei known as "clover leaf" or "flower cells." For immunophenotype, the origin of the malignant cell in ATLL is an HTLV-Iinfected memory CD4+ $\mathrm{T}$ lymphocyte which expresses CD2, CD3, CD4, and CD25 in most cases. CD52 is often expressed. Genetic sequencing showed somatic mutations in RHOA and TET2, loss-offunction mutations in TP53, and overexpression of PD-L1 [12].

\section{Biomarker-driven therapeutic strategies in $\mathbf{R} / \mathbf{R}$ PTCL}

In addition to contribution to classification and diagnosis of PTCL subtypes, biomarkers provide critical insights into the pathogenic pathways and biological rationale for novel therapeutic intervention (Fig. 1, Tables 1, 2, 3, and 4).

\section{Targeting cell surface receptors \\ CD30}

CD30 is a tumor necrosis factor (TNF) receptor family transmembrane receptor with restricted expression in activated $\mathrm{T}$ and $\mathrm{B}$ cells in normal lymphoid tissues [13]. Across PTCL subtypes, systemic ALCLs universally express CD30 in membrane and golgi patterns, while approximately $50 \%$ of non-ALCL subtypes, including PTCL, NOS, AITL, ENKTL, ATLL, EATL, and HSTL, express CD30 at variable levels. CD30 expression in PTCL suggests a CD30-mediated pathogenic mechanism for potential therapeutic targeting with brentuximab vedotin (BV), an antibody-drug conjugate that combines cytotoxic monomethylauristatin E (MMAE) with an anti-CD30 antibody [14]. The level of CD30 expression may not always be predictive of response to BV due in part to tumor heterogeneity, variation in detection and reporting of CD30 expression, and proposed secondary mechanisms of action. Single-agent BV given at $1.8 \mathrm{mg} /$ $\mathrm{kg}$ intravenously every 3 weeks for up to 16 cycles in 58 patients with relapsed or refractory (R/R) sALCL showed overall response rate (ORR) of $86 \%$ with $57 \%$ complete response (CR) in a pivotal phase 2 study, leading to approval in the USA, EU, and Japan for R/R sALCL [15]. Responses in SALCL appear to be durable: 5 -year overall survival (OS) and progression-free survival (PFS) were $79 \%$ and $57 \%$, respectively, in patients who achieved a CR. In patients who did not achieve a CR, the 5-year OS was $25 \%$ [15]. Grade 3 or 4 adverse events (AEs) experienced by $\geq 10 \%$ of patients were neutropenia (21\%), thrombocytopenia (14\%), and peripheral sensory neuropathy (12\%). Overall, treatment was well tolerated. In non-ALCL, single-agent BV showed clinical antitumor activity in AITL and PTCL-NOS, with ORR of $41 \%$ (including 54\% ORR in AITL with a median PFS of 6.7 months), although responses did not correlate with CD30 expression [16]. These results with single-agent BV paved the way for clinical development of BVcontaining combinations in both relapsed and frontline settings.

\section{CD52}

CD52 is a glycosylphosphatidylinositol (GPI) anchored low molecular weight glycoprotein $(21-28 \mathrm{kDa})$ expressed on the surface of $\mathrm{B}$ and $\mathrm{T}$ lymphocytes, natural killer cells, monocytes, macrophages, and some dendritic cells [17]. PTCL subtypes such as PTCL/NOS, AITL, ATLL, HSTL, and T-PLL were shown to have high frequency of CD52 expression (>90\%) by flow cytometry and IHC analysis, while CD52 expression was low in ALCL and ENT/NKCL [18, 19]. Although the variable and differential CD52 expression in $\mathrm{T}$ cell lymphoma tumor cells implies a rational role for antiCD52 mAb alemtuzumab in the treatment of PTCL, persistent expression of CD52 by the background normal $\mathrm{T}$ - and $\mathrm{B}$ cell infiltrate limits therapeutic window of anti-CD52 therapy due to potential immunosuppression, including increased risk of viral and other opportunistic infections [20].

Single-agent alemtuzumab has established treatment efficacy in T cell prolymphocytic leukemia (T-PLL). Phase $\mathrm{I} / \mathrm{II}$ and retrospective studies have indicated response rates of up to $75 \%$ in patients with previously untreated disease, although relapse remains nearly universal with mOS of $<$ 2 years. When given three times weekly at 3,10 , and 30 mg IV during week one, followed by $30 \mathrm{mg}$ three times a week for up to 16 weeks, response rate was over $90 \%$ in 41 previously untreated T-PLL patients with $81 \%$ achieving CRs [21]. Prophylaxis against pneumocystis jiroveci (PJP) and herpes viruses together with regular monitoring for CMV reactivation are recommended to minimize the risk for serious infections [22].

\section{CCR4}

CC chemokine receptor 4 (CCR4) promotes memory $\mathrm{T}$ cell homing to peripheral tissues and is preferentially expressed by Th2 and regulatory $\mathrm{T}$ cell subsets [24]. In addition to expression in most CD4+CD25+ ATLL, CCR4 is expressed in approximately $30-65 \%$ of PTCL tumor cells, including high expression $(\sim 65 \%)$ in ALKnegative ALCL, variable expression (30-40\%) in PTCL/ NOS, AITL, and transformed MF, while rarely expressed in ENKTL or ALK-positive ALCL [25]. Mogamulizumab (KW-0761) is a defucosylated, humanized, IgG1 monoclonal antibody directed against CCR4 that has direct cytotoxic effect on CCR4-positive lymphoma cells via ADCC, as well as immunomodulatory potential by 


\section{Biomarker Driven Strategies in Peripheral T-cell Lymphoma}

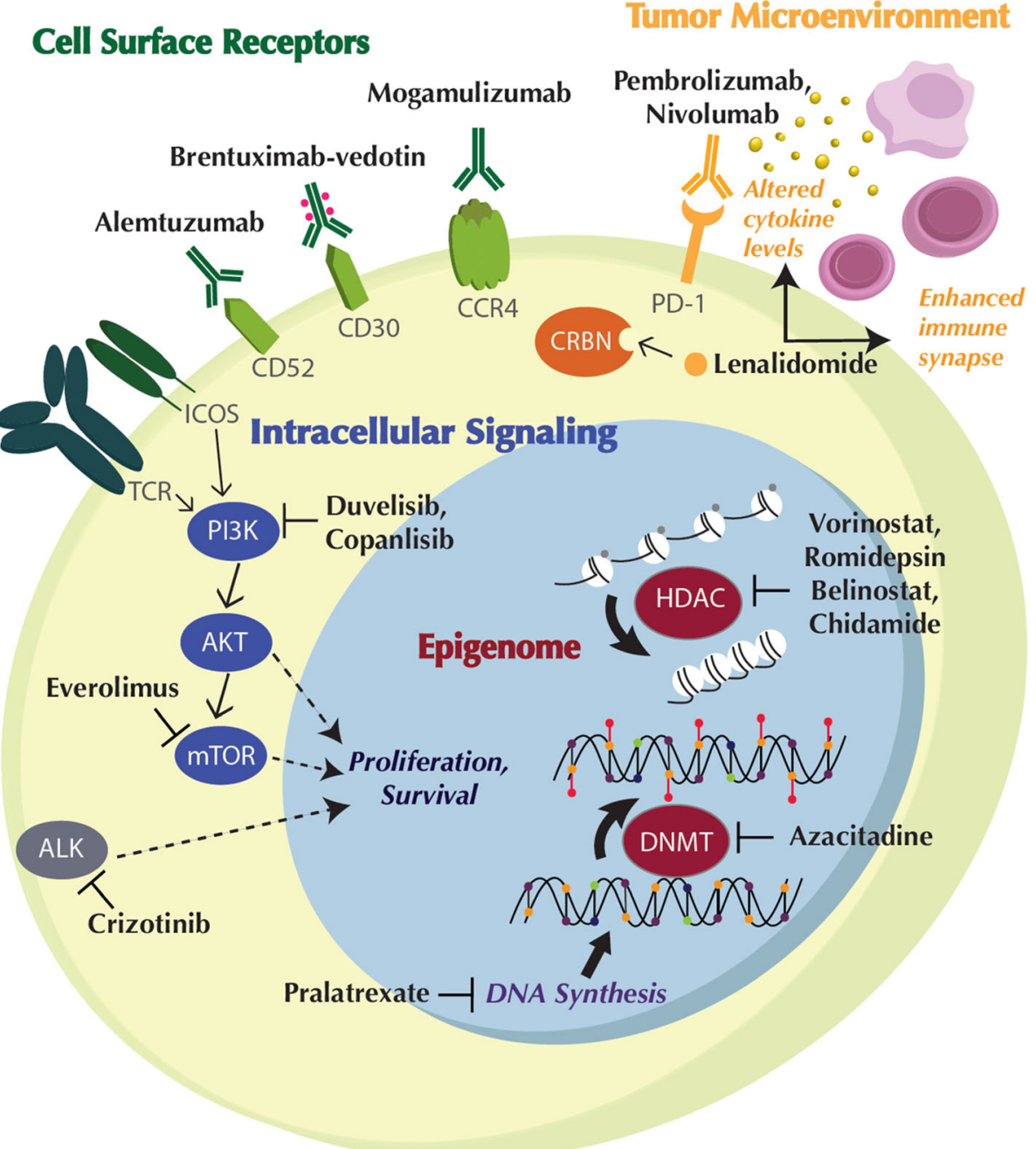

Fig. 1 Biomarker-driven strategies in peripheral T cell lymphoma. Positive and inhibitory interactions are depicted as solid arrows and bar-headed lines, respectively. The protein symbols of genes appear inside colored ovals. ALK, oncogenically activated anaplastic lymphoma kinase. AKT, protein kinase B. CCR4, chemokine receptor 4. CD30, cluster of differentiation 30. CD52, cluster of differentiation 52. CRBN, cereblon. DNMT, DNA methyltransferase. HDAC, histone deacetylase. ICOS, inducible T cell co-stimulator. mTOR, mammalian target of rapamycin. PD-1, programmed death receptor 1. PI3K, phophoinositide 3-kinase. TCR, T cell receptor

depletion of regulatory $\mathrm{T}$ cells to enhance anti-tumor immunity. Mogamulizumab is approved in Japan for R/R CCR4+ ATLL and CTCL and has been approved in the USA for R/R MF and Sezary syndrome. In 28 Japanese patients with CCR4+ R/R ATLL treated with mogamulizumab at $1.0 \mathrm{mg} / \mathrm{kg}$ intravenously once weekly for 8 weeks demonstrated ORR of $50 \%$ with $30 \%$ CR, and median PFS and OS of 5.2 and 13.7 months, respectively [26]. The most common AEs were hematologic events, pyrexia, and skin reactions, all of which were reversible and manageable.

\section{Targeting the epigenome}

Emerging genetic studies with gene expression profiling (GEP) and next-generation sequencing (NGS) have shown recurrent mutations in epigenetic regulators which contribute to lymphomagenesis and may represent the target of tailored therapies such as epigenetic modifiers [2].

\section{HDAC inhibitors}

In preclinical studies using TCL cell lines, HDAC inhibitors were shown to induce cell-cycle arrest, apoptosis, and DNA damage and modulate a number of 
intracellular pathways [28]. Vorinostat, a pan HDAC, was the first drug of its class to be approved by the FDA in 2006 for the treatment of cutaneous $T$ cell lymphoma. A single-arm open-label phase II trial enrolled 74 patients with stage IB or greater CTCL who had failed 2 or more lines of systemic therapy including bexarotene. Patients were treated with oral vorinostat at $300 \mathrm{mg}$ daily or $300 \mathrm{mg} 5$ days a week and demonstrated favorable responses and an acceptable safety profile: ORR $30 \%$ and a median time to tumor progression 202 days [29]. This approval ushered in a still ongoing period of research and development of epigenetic therapy, particularly in TCL.

Romidepsin is a bicyclic class 1 selective HDAC inhibitor approved by the FDA for treatment in patients with $\mathrm{R} / \mathrm{R}$ PTCL who have failed at least one prior systemic therapy. In a pivotal phase 2 study, 130 patients received romidepsin at $14 \mathrm{mg} / \mathrm{m}^{2}$ on days 1,8 , and 15 every 28 day cycle, which showed ORR of $25 \%$ including $15 \%$ CR/ unconfirmed $\mathrm{CR}(\mathrm{CRu})$, with durable median duration of response (DOR) of 28 months in responders [30, 31]. Adverse events were manageable and consistent with other HDAC inhibitors, with thrombocytopenia (24\%), neutropenia (20\%), and infections (all types, 19\%) representing the most common grade $\geq 3$ AEs. Given the promising results of this study, romidepsin has also been combined with other agents, such as lenalidomide [32], carfilzomib [33], or pralatrexate [34], in attempts to improve efficacy. A phase I/II trial, which included 11 patients with R/R PTCL, showed an ORR of $50 \%$ to the doublet of romidepsin given at MTD of $14 \mathrm{mg} / \mathrm{m}^{2} \mathrm{IV}$ on days 1,8 , and 15 and lenalidomide $25 \mathrm{mg}$ orally on days 1-21 of 28-day cycles [32]. Romidepsin has additionally been combined with lenalidomide and carfilzomib as a triplet in a phase Ib/IIa study that included 16 patients with R/R PTCL. MTD was defined as romidepsin $8 \mathrm{mg} /$ $\mathrm{m}^{2}$ days 1 and 8 , lenalidomide $15 \mathrm{mg}$ days $1-15$, and carfilzomib $36 \mathrm{mg} / \mathrm{m}^{2}$ days 1 and 8 , every 21 -day cycle. The triplet demonstrated a 50\% ORR with $30 \%$ CR, which seemed to be enriched among patients with AITL (4/5 patients) [33]. A phase I trial combining romidepsin 15 $\mathrm{mg} / \mathrm{m}^{2}$ and pralatrexate $25 \mathrm{mg} / \mathrm{m}^{2}$ in 18 patients with $\mathrm{R} /$ R PTCL showed ORR of $71 \%$, which has led to an ongoing phase II trial (NCT01947140) in PTCL [34].

Belinostat, a hydroxamic acid-derived pan-HDAC inhibitor, has also been approved by the FDA in 2014 based on the results of the pivotal phase 2 BELIEF trial [35]. A total of 129 patients with R/R PTCL were treated with $1000 \mathrm{mg} / \mathrm{m}^{2}$ belinostat on days $1-5$ in 21 -day cycles. The ORR was $25.8 \%$ including $10.8 \%$ CRs. The ORR was $23 \%$ in patients with PTCL-NOS, $46 \%$ in patients with AITL, and $15 \%$ in patients with ALK- ALCL. The median DOR was 13.6 months, and median PFS and OS were 1.6 and 7.9 months, respectively. The most common grade 3 to 4 adverse events were anemia (10.8\%), thrombocytopenia (7\%), dyspnea (6.2\%), and neutropenia (6.2\%).

The oral class I/II HDAC inhibitor chidamide has been studied in $83 \mathrm{R} / \mathrm{R}$ PTCL patients in China in a phase II study, which included patients with PTCL NOS (34\%), ALCL $(22 \%)$, ENKTL, nasal type (20\%), or AITL (13\%). Patients received chidamide $30 \mathrm{mg}$ orally twice per week. The ORR was $28 \%$ including $14 \%$ with CR/CRu. Median PFS and OS were 2.1 and 21.4 months, respectively. AITL patients tended to have higher ORR (50\%) and CR/CRu rate $(40 \%)$, as well as more durable responses to chidamide treatment, with a manageable toxicity profile [36].

\section{Hypomethylating agents}

5-Azacitidine (5-AZA) has shown efficacy in myeloid neoplasms where response rates appear to correlate with TET2, IDH1/2, and/or DNMT3A mutations which regulate DNA methylation levels [37]. It was hypothesized that hypomethylating agents could be effective in TFH-derived PTCL given the abundance of recurrent TET2, DNMT3A, and $I D H 2$ mutations. A retrospective French LYSA cohort study reported clinical outcome of 12 patients with $R / R$ AITL (41\% with associated myeloid neoplasms) treated with subcutaneous daily injection of $75 \mathrm{mg} / \mathrm{m}^{2} 5$-AZA for 7 consecutive days every 28-daycycle. The treatment appeared to be promising: ORR was $75 \%$ including $50 \% \mathrm{CR}$, median PFS was 15 months, and median OS was 21 months. Molecular studies revealed TET2 mutation in $100 \%$ of patients, $33 \%$ with DNMT3A mutations, $41 \%$ with RHOA mutations, and one patient with $I D H 2^{R 172}$ mutation [38]. Currently, a global phase 3 study is ongoing to prospectively compare the efficacy and safety of oral azacitidine (CC486) to the investigator's single-agent choice of either romidepsin, bendamustine, or gemcitabine in patients with R/R AITL (NCT03593018). Azacitadine has also been studied in combination with romidepsin in a multicenter phase I trial. Azacitadine was given orally at a MTD of $300 \mathrm{mg}$ on days 1 to 14 with romidpesin $14 \mathrm{mg} / \mathrm{m}^{2}$ given IV on days 8 , 15 , and 22 on a 35-day cycle in 31 patients with R/R lymphomas. This pair was particularly effective in PTCL, where it produced ORR of $73 \%$ with $55 \% \mathrm{CR}$ and was well tolerated [39]. A phase II study with this combination is maturing to confirm the efficacy data in PTCL.

\section{Targeting tumor microenvironment PD1/PD-L1}

PD1 is a type I membrane protein that belongs to the immunoglobulin superfamily. It is a member of the extended CD28/CTLA-4 family of immune checkpoint that guards against autoimmunity by downregulating the immune system and promoting self-tolerance [40]. PD-1 is expressed on the surface of activated T cells, B cells, and macrophages and negatively regulates immune responses broadly. PD1 binds two ligands, PD-L1 and PD-L2. In 
PTCL, PD-1 expression was detected in atypical T lymphoma cells in the majority of AITL (>90\%), to a lesser extent in PTCL/NOS (30-60\%), and rarely in other subtypes [41]. In AITL, both PD1 and CXCL13, a chemokine promoting B cell migration and survival in lymph node, showed a similar expression frequency highlighting follicular helper $\mathrm{T}$ cells (TFH) [42], which may share additional TFH markers including CD10, BCL6, and ICOS [43]. In NKTCL, PD-L1 expression in NK/T cell lymphoma cells ranged from 56 to $93 \%$ in various studies, while PD-1 level was low [44]. In ATLL, PD-L1 amplification was shown as a strong genetic predictor in both aggressive and indolent ATLL [45]. Anti-PD1 immune checkpoint blockade strategy has generated mixed results in PTCL to date due to the complexity that malignant $\mathrm{T}$ cell lymphoma cells can express PD-1. In such instances, immune checkpoint blockade has the potential to accelerate tumor growth in tumor cells with high PD-1 expression, as proposed in murine studies [46]. ATLL patients treated with nivolumab developed rapid disease progression after 1 cycle of nivolumab treatment [47], cautioning against the use of immune checkpoint blockade in ATLL without further understanding the complex mechanism of immune evasion and activation. In other subtypes, responses have been mixed. In patients with R/R $\mathrm{T}$ cell lymphoma, singleagent nivolumab produced ORR of 40\% [48], while PD1 blockade with pembrolizumab showed high efficacy (100\% ORR, $71 \% \mathrm{CR}$ ) in a case series of $7 \mathrm{R} / \mathrm{R}$ EBV-associated NK and T cell lymphoma [49]. A phase II multicenter trial of patients with R/R PTCL who were treated with pembrolizumab was halted early after a preplanned interim futility analysis [49]. Nevertheless, several trials are ongoing to further explore the efficacy of PD-1 blockade in PTCL. Pembrolizumab is being added to romidepsin (NCT03278 782) and pralatrexate (NCT03598998) in ongoing phase I/ II trials in patients with R/R PTCL. Pembrolizumab is also being combined with pralatrexate and the epigenic modifier decitabine in an ongoing phase I trial (NCT03240211). The PD-1 monoclonal antibody durvalumab is being studied alone and in combination with lenalidomide in patients with R/R PTCL and CTCL (NCT03011814) as well as in combination with pralatrexate, romidepsin, and/or azacitdine (NCT03161223). The novel PD-1 monoclonal antibodies avelumab (NCT03046953) and tislelizumab (NCT03493451) are being evaluated in R/R PTCL and R/R mature NK and $\mathrm{T}$ cell lymphomas, respectively.

\section{Immunomodulatory agents}

Lenalidomide is a well-established immunomodulatory agent in B cell NHL and multiple myeloma, which has shown modest single-agent activity in PTCL in phase 2 studies. The EXPECT trial with lenalidomide $25 \mathrm{mg}$ given once daily on days 1-21 of 28-day cycle showed ORR of $22 \%$ with $11 \% \mathrm{CR} / \mathrm{Cru}$ in various $\mathrm{R} / \mathrm{R} \mathrm{PTCL}$ subtypes, including ORR $31 \%$ with CR/Cru $15 \%$ in AITL [50]. Overall, 35\% of patients experienced at least $1 \mathrm{AE}$ that lead to study dose interruption or reduction, most commonly neutropenia or thrombocytopenia. Lenalidomide given at $25 \mathrm{mg}$ daily continuously in a phase 2 study of Japanese patients with R/R ATLL showed ORR of $42 \%$ with $19 \% \mathrm{CR} / \mathrm{CRu}$, and median PFS and OS at 3.8 and 20.3 months, respectively. Toxicities were manageable in this population with all serious AEs resolving or resolved by the end-of-study assessment [51].

\section{Targeting signaling and proliferation pathways ALK}

Anaplastic lymphoma kinase (ALK) is a receptor tyrosine kinase known to be oncogenically activated in a subset of ALCL. Crizotinib is an ALK-ROS1-MET small molecule inhibitor which showed a high response rate (ORR 90\%) in the Children's Oncology Group study of 26 ALK+ ALCL patients [33, 52]. In this prospective phase I/II trial, patients were treated with crizotinib at $165 \mathrm{mg} / \mathrm{m}^{2}$ or $280 \mathrm{mg} / \mathrm{m}^{2}$ orally twice daily on days $1-$ 28 of 28-day cycles. CR was observed in $83 \%$ (five of six) of ALCL165 and 80\% (16 of 20) of ALCL280, with a median duration of therapy of 2.79 and 0.4 years, respectively. A retrospective study of 11 adult patients with $R / R$ ALK+ lymphoma treated with crizotinib $250 \mathrm{mg}$ twice daily until disease progression achieved $90.9 \%$ ORR with OS and PFS at 2 years of $72.7 \%$ and $63.7 \%$, respectively [53]. Crizotinib-related toxicities were mild and manageable. These studies highlight the important role the ALK pathway plays in these diseases.

\section{PI3K inhibitors}

Phosphatidylinositol 3-kinase (PI3K) is a lipid kinase that is involved in intracellular signal transduction, with the PI3K- $\delta$ and PI3K- $\gamma$ isoforms preferentially expressed in leukocytes where they modulate both innate and adaptive immune function by mediating pathways important for survival, proliferation, and differentiation [54, 55]. Specifically, inhibition of PI3K- $\delta$ and PI3K- $\gamma$ isoforms blocks mitogenic and survival within tumor cells, disrupts interaction with the tumor microenvironment, and restores antitumor immune responses. The PI3K $\delta / \gamma$ inhibitor duvelisib was evaluated in a phase I dose-escalation trial in 16 patients with R/R PTCL at a MTD of $75 \mathrm{mg}$ twice daily on a 28 -day cycle where it resulted in a $50 \%$ ORR with 3 CRs. The median PFS was 8.3 months, with activity demonstrated across a number of subtypes [56], and a phase II trial is underway (NCT03372057). Duvelasib is also being studied in combination with romidepsin and bortezomib in a parallel phase I study in patients with PTCL and CTCL. Duvelasib is given at $75 \mathrm{mg}$ twice daily on days $1-28$ on 28 -day cycles with either romidepsin 10 $\mathrm{mg} / \mathrm{m}^{2}$ on days 1,8 , and 15 (arm A) or with bortezomib 1 
$\mathrm{mg} / \mathrm{m}^{2}$ on days $1,4,8$, and 11 (arm B) [56, 57]. These combinations show activity with ORR and CR rates of $55 \%$ and $27 \%$ for patients with PTCL treated on arm A, and $36 \%$ and $21 \%$, respectively, in patients treated on arm B. The median PFS and OS were 8.8 months and 9.1 months for PTCL patients on arm A and 3.5 months and 9.3 months for patients on arm B. Of note, $65 \%$ of patients treated on arm A experienced grade 3 or higher adverse events (AEs) with neutropenia (18\%) and elevated transaminases (15\%) being the most frequent. Among patients treated on arm B, $45 \%$ experienced grade 3 or higher AEs with neutropenia (18\%) occurring in more than $10 \%$ of patients. A phase IB dose-escalation study is being planned to examine the combination of romidepsin with the PI3K $\alpha / \delta$ inhibitor copanlisib (NCT04233697). The PI3K- $\delta$ inhibitor YY-20394 is being evaluated in an ongoing phase I trial in patients with R/R PTCL (NCT04108325).

\section{mTOR inhibitors}

Everolimus is an oral agent that inhibits the mammalian target of rapamycin (mTOR) pathway and has been shown to strongly inhibit malignant $\mathrm{T}$ cell proliferation in vitro [58]. Single-agent everolimus given at $10 \mathrm{mg}$ daily continuously has been studied in a phase II trial including 16 patients with R/R PTCL with a variety of subtypes, including 4 PTCL-NOS, 2 ALCL, and 1 each had extranodal NK/T cell, AITL, and precursor TLL lymphoma. Everolimus resulted in an ORR of $44 \%$ with a median PFS of 8.5 months and an overall survival of 10.2 months. Among responders, the median DOR was 8.5 months [58]. Dose reduction to $5 \mathrm{mg}$ daily was required in $35 \%$ of patients.

\section{Aurora kinase inhibition}

Aurora A kinase (AAK) is a mitotic oncogenic serine/threonine kinase that plays an essential role in progression through the cell cycle during mitosis and has been shown to be upregulated in aggressive lymphomas [59-61]. Alisertib is an oral AAK inhibitor that was studied in the SWOG1108 phase II trial which included 37 patients with R/R PTCL or transformed mycoses fungoides [62]. Patients received alisertib $50 \mathrm{mg}$ twice daily for 7 days every 21-day cycle, resulting in a 30\% ORR with 7\% CRs, and median PFS and OS of 3 months and 8 months respectively [64]. Consistent with earlier phase I data, myelosuppression was common (in up to $32 \%$ of patients) and was the most common reason for dose reductions. The phase III Lumiere trial compared single-agent alisertib to investigator's choice of single-agent of pralatrexate, gemcitabine, or romidepsin [63]. Alisertib showed similar results with an ORR of 33\% with $16 \%$ CR, a median PFS of 2.7 months, and a median OS of 9.9 months. Based on preclinical data suggesting synergism [64], alisertib was studied in combination with romidepsin in a phase I trial of $R / R$ aggressive lymphomas including 4 patients with PTCL. While the primary endpoint of the study was to demonstrate safety and tolerability, this combination resulted in disappointing results in these heavily pretreated PTCL patients, with no CRs or PRs [65].

\section{Antifolates}

Pralatrexate, a folate analogue metabolic inhibitor that selectively enters cells through reduced folate carrier type 1 (RFC-1), was studied in the pivotal multicenter phase II PROPEL trial [66]. Patients with R/R PTCL were treated with weekly pralatrexate $30 \mathrm{mg} / \mathrm{m}^{2}$ infusions for 6 weeks in 7 -week cycles. The response rate among the 109 evaluable patients was $29 \%$, including 12 complete responses (11\%) and 20 partial responses (18\%), with a median DoR of 10.1 months. Median PFS and OS were 3.5 and 14.5 months, respectively. Pralatrexate received FDA's approval for R/R PTCL in 2009.

\section{Therapies available and under investigation to target biomarkers in frontline PTCL}

CHOP (cyclophosphamide, doxorubicin, vincristine, and prednisone) is the most commonly prescribed initial therapy for PTCL, despite results showing that the majority of PTCL patients have an inferior outcome compared with their B cell counterparts receiving CHOP, with the exception of ALK-positive ALCL. Data from the international T cell project showed that the 5-year OS for PTCL-NOS, AITL, and NKTCLs was $32 \%$ compared with $14 \%$ for ATLL. ALK-positive ALCL demonstrated 5-year OS of $70 \%$, compared to $49 \%$ with ALK-negative ALCL [1]. There is a paucity of prospective randomized trials comparing alternative chemotherapy combinations with $\mathrm{CHOP}$ in frontline setting, given disease rarity and heterogeneity. The German High-Grade Non-Hodgkin Lymphoma Study Group, in a retrospective ad hoc analysis of over 300 patients with PTCL, showed that the addition of etoposide to CHOP (CHOEP) improved the EFS of patients younger than 60 who had ALCL and normal LDH levels. Other subgroups of patients did not appear to significantly benefit from this addition [67]. To date, standard-dose CHOP remains the reference regimen in PTCL treatment. Efforts to improve frontline therapy in PTCL have been focused on several strategies: (1) to improve upon CHOP by incorporating novel agent $\mathrm{X}$ into $\mathrm{CHOP}$ chemotherapy backbone, whereas $\mathrm{X}$ denotes therapeutic targeting of surface biomarkers such as CD30 and CD52, or epigenetic modifiers regulating essential pathogenic pathways involving modification of histone acetylation and methylation; (2) to explore novel combination free of conventional chemotherapy; and (3) to experiment with novel agents for consolidation and maintenance following chemotherapy induction. 
Biomarker-driven strategies to improve CHOP-based induction chemotherapy

Targeting CD30-positive PTCL with brentuximab vedotin plus chemotherapy

The feasibility of adding BV to CHOP in first-line setting was evaluated in a phase 1 study with BV $1.8 \mathrm{mg} / \mathrm{kg}$ administered either sequentially with standard-dose $\mathrm{CHOP}$ $(\mathrm{BV} \times 2$ cycles, followed by $\mathrm{CHOP} \times 6$ cycles $)$ or in combination with $\mathrm{CHP}$ (CHOP without vincristine) for $6 \mathrm{cy}$ cles in patients with mostly CD30-expressing ALCL. Responders received single-agent brentuximab vedotin for $8-10$ additional cycles (for a total of 16 cycles) [68]. The ORR was $85 \%$ (CR 62\%) with sequential treatment, and ORR was $100 \%$ (CR 88\%) with combination treatment. Safety profile was manageable. Durable remission at 5 years was noted in $50 \%$ of patients without subsequent anti-cancer therapy [69]. Based on this encouraging phase 1 data, a global double-blind, randomized phase 3 study (ECHELON-2, NCT01777152) was initiated in 2013 comparing BV-CHP with standard CHOP in untreated CD30-positive PTCL (targeting 75\% ALCL) [70], and randomized 452 patients. BV-CHP was associated with higher CR rate (68\% vs $56 \%, p=0.0066)$ and superior survival. Median PFS was 48.2 months in the BV-CHP group, significantly improved compared to 20.8 months in the CHOP group. In addition, BV-CHP reduced the risk of death by $34 \%$ compared with $\mathrm{CHOP}$. Adverse events, including febrile neutropenia and peripheral neuropathy, were similar between groups. ECHELON-2 is the first randomized phase 3 study establishing the superiority of BV-CHP over $\mathrm{CHOP}$ in untreated PTCL, which led to FDA approval in November 2018 of BV-CHP as frontline therapy for CD30-positive PTCL. Although the ECHELON-2 study included nonALCL cases such as PTCL-NOS, AITL, ATLL, and EATL ( $30 \%$ enrollment, 136 total), their small sample sizes precluded sufficient power analysis.

\section{Targeting CD52-positive PTCL}

Given the variable expression of CD52 in PTCL subtypes, a prospective multicenter trial evaluated the feasibility and clinical efficacy of the combination of alemtuzumab with $\mathrm{CHOP}$ regimen $(\mathrm{CHOP}-\mathrm{C})$ as the primary treatment for 24 patients with peripheral $\mathrm{T}$ cell lymphoma (PTCL) that included PTCL/NOS, AITL, ALK-negative ALCL, and EATL [71]. Patients received 8 CHOP courses, with alemtuzumab given at $30 \mathrm{mg}$ subcutaneously at day 1 prior to $\mathrm{CHOP}$ given at standard 21-day cycle. Complete remission (CR) was achieved in 17 (71\%) patients, 2-yr OS was estimated at 53\% and 2$\mathrm{yr}$ PFS at $48 \%$. Despite promising CR rate, alemtuzumab-containing therapy was accompanied by substantial immunosuppression and infectious complications. Similar findings were noted in more intensive combinations of alemtuzumab plus either CHOP-14 (HOVON) [72] or DA-EPOCH (etoposide, prednisone, vincristine, cyclophosphamide, and doxorubicin) [73]. Twenty patients were treated on the phase $2 \mathrm{HOVON}$ alemtuzumab-CHOP14 study, which showed ORR of 90\%; CR 60\%; 2 -year OS and EFS at 55\% and 27\%, respectively; high rates of neutropenic fever $(40 \%)$; and CMV reactivation (35\%), as well as secondary EBVrelated lymphoma (15\%) [72]. Thirty patients were treated on the phase $1 / 2 \mathrm{NCI}$ alemtuzumab with DAEPOCH study. CR was achieved in 17 (57\%) patients, and ORR was $83 \%$, with median OS and PFS at 20.2 and 6.6 months, respectively. There were five treatmentrelated deaths on study due to infectious complications [73]. Phase 3 studies comparing the addition of alemtuzumab to CHOP14 versus CHOP14 alone in younger (ACT-1, NCT00646854) and elderly (ACT-2, NCT00725231) patients could not reach planned sample sizes due to low recruitment, and combined analysis of ACT-1 and ACT-2 studies of 252 patients showed no significant difference in EFS, PFS, and OS, while alemtuzumab-CHOP was associated with more infections.

\section{Targeting epigenetic pathways}

HDAC inhibitors Feasibility of HDAC inhibitors with $\mathrm{CHOP}$ combination has been evaluated with romidepsin, belinostat, and chidamide in the first-line setting. In the phase Ib/II LYSA study of romidepsin-CHOP combination, the RP2D for romidepsin was $12 \mathrm{mg} / \mathrm{m}^{2}$ on days 1 and 8 of each cycle for 8 cycles. High CR rate (51\%) was achieved with 30 -month PFS of $41 \%$ and 30 -month OS of $70.7 \%$ [35], which forms the basis for the ongoing phase 3 LYSARC study (NCT01796002) evaluating survival and response with 6 cycles of Ro-CHOP compared to standard CHOP. The outcome of this phase 3 study is maturing and highly awaited, especially with regard to non-ALCL PTCL subtypes including AITL in the context of ECHELON-2 data which enrolled mostly ALCL patients. The addition of romidepsin to CHOEP is also being evaluated in ongoing phase I/II study in young patients with nodal PTCL prior to proceeding with hematopoetic stem cell transplant (NCT02223208).

The combination of belinostat plus CHOP in frontline setting was explored as well, with phase 3 study of BelCHOP planned [74]. The oral HDAC inhibitor chidamide was evaluated in a phase $1 \mathrm{~b} / 2$ study in combination with $\mathrm{CHOP}$ in China [75]. Patients received one dose chidamide as the run-in treatment, followed 4 days later by CHOP (6 cycles, each 21 days) with chidamide on days 1 , 4, 8, and 11 at MTD of $30 \mathrm{mg}$. Patients achieving a CR/ Cru following induction treatment received consolidation 


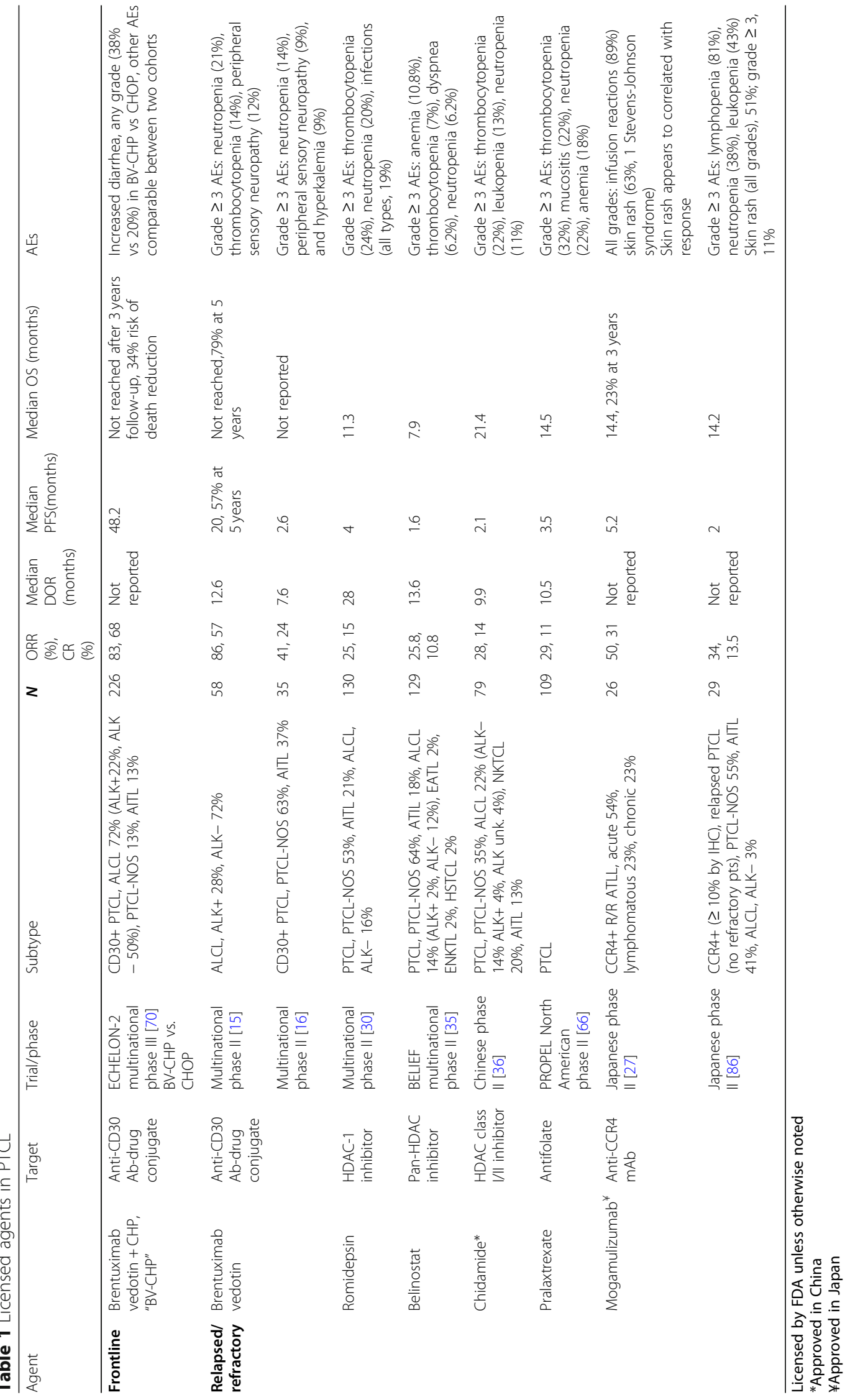




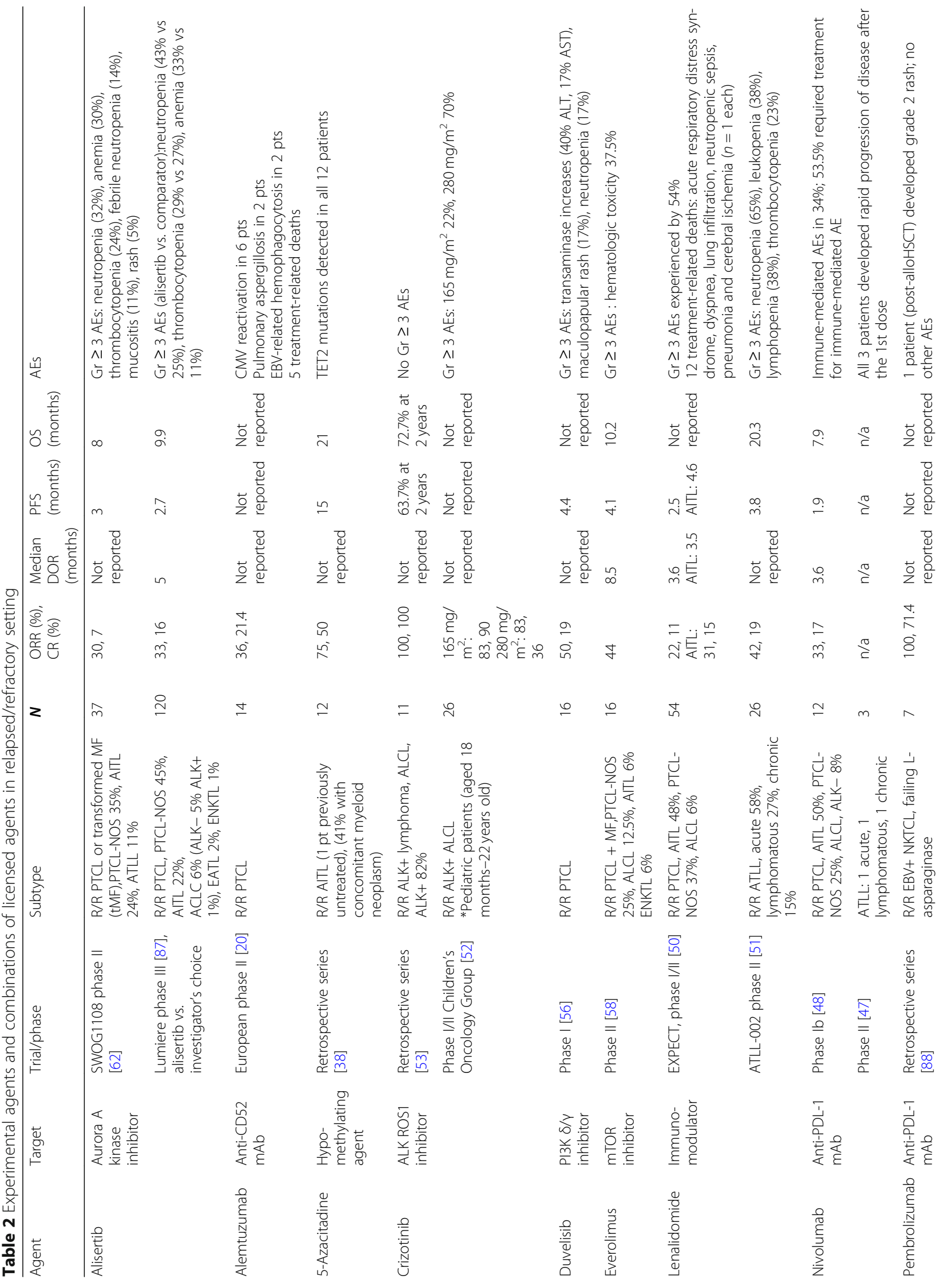


Mulvey and Run Journal of Hematology \& Oncology

(2020) 13:59

Page 11 of 20

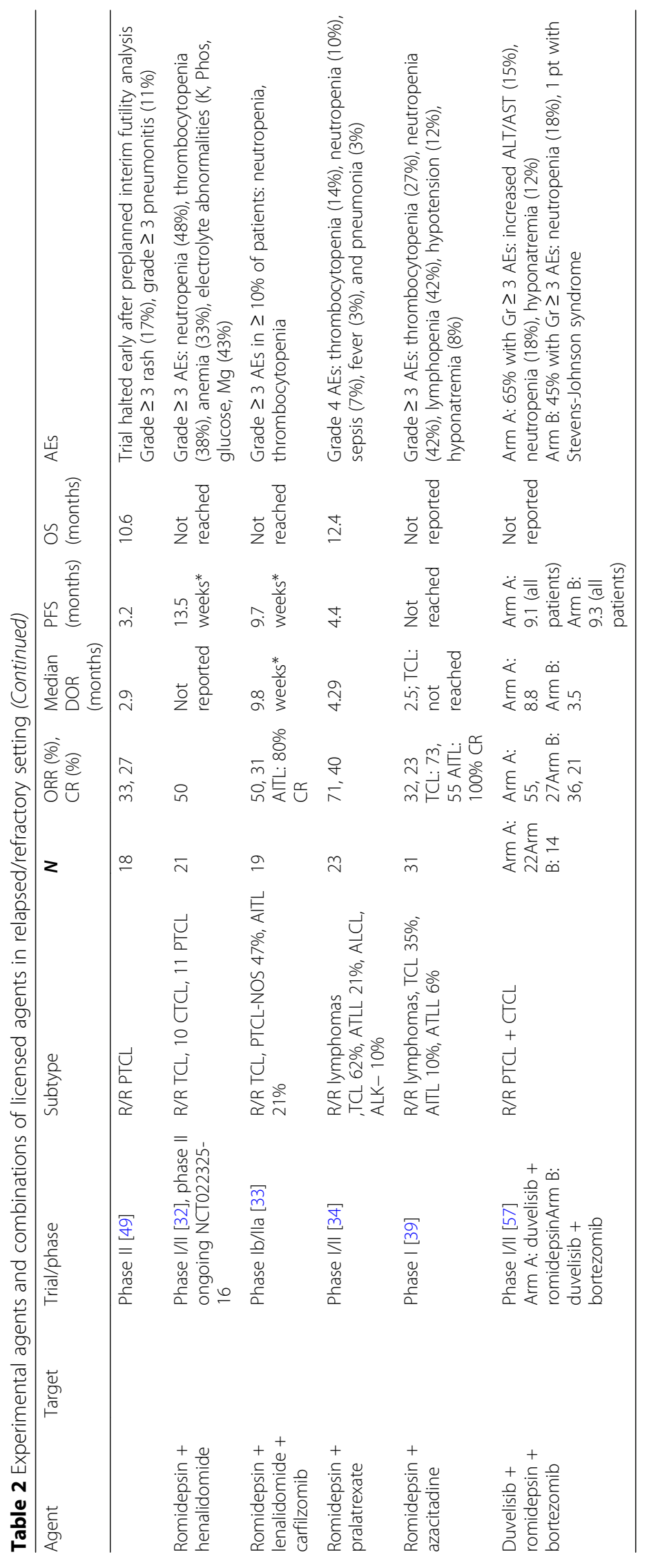




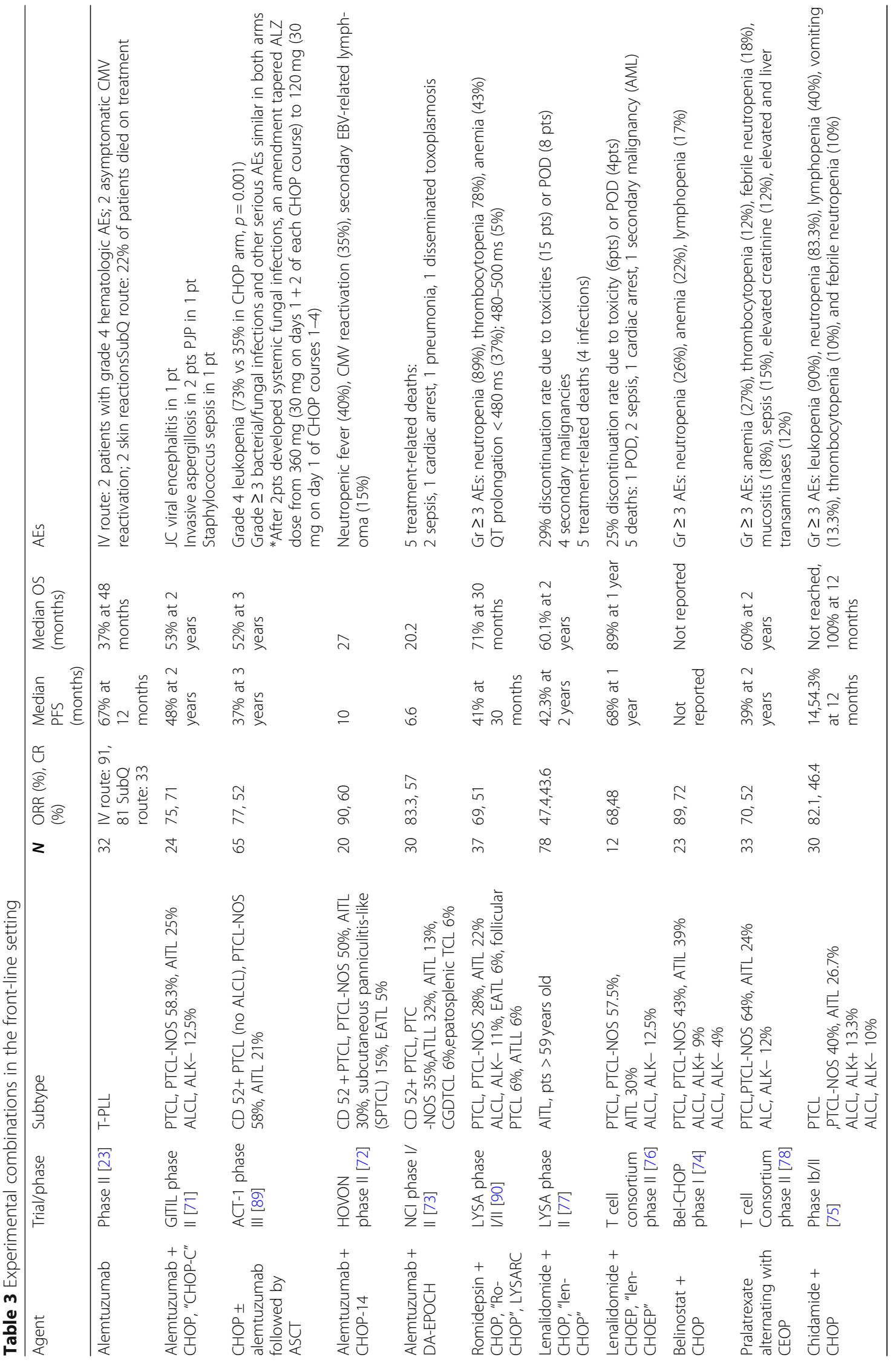




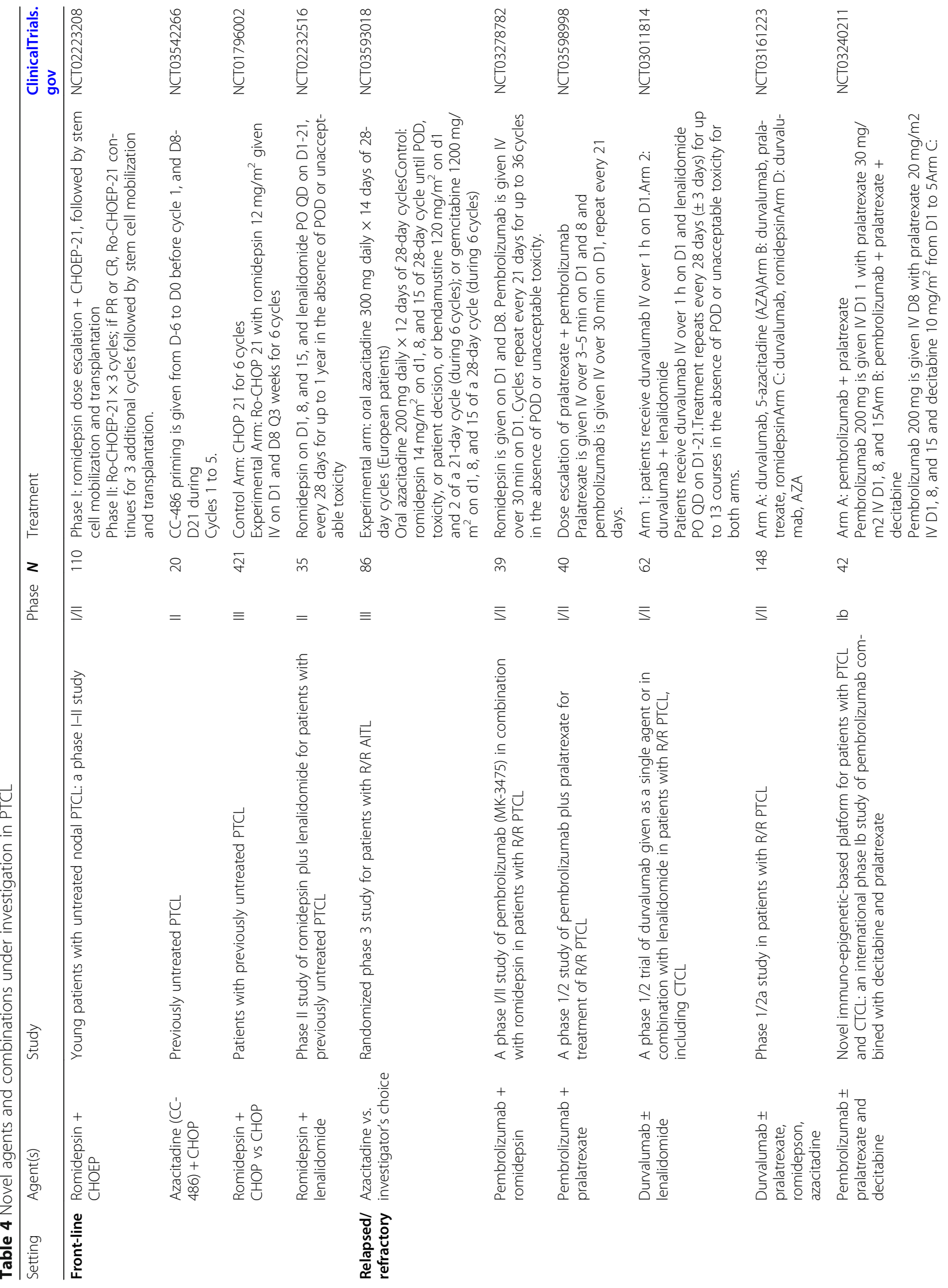




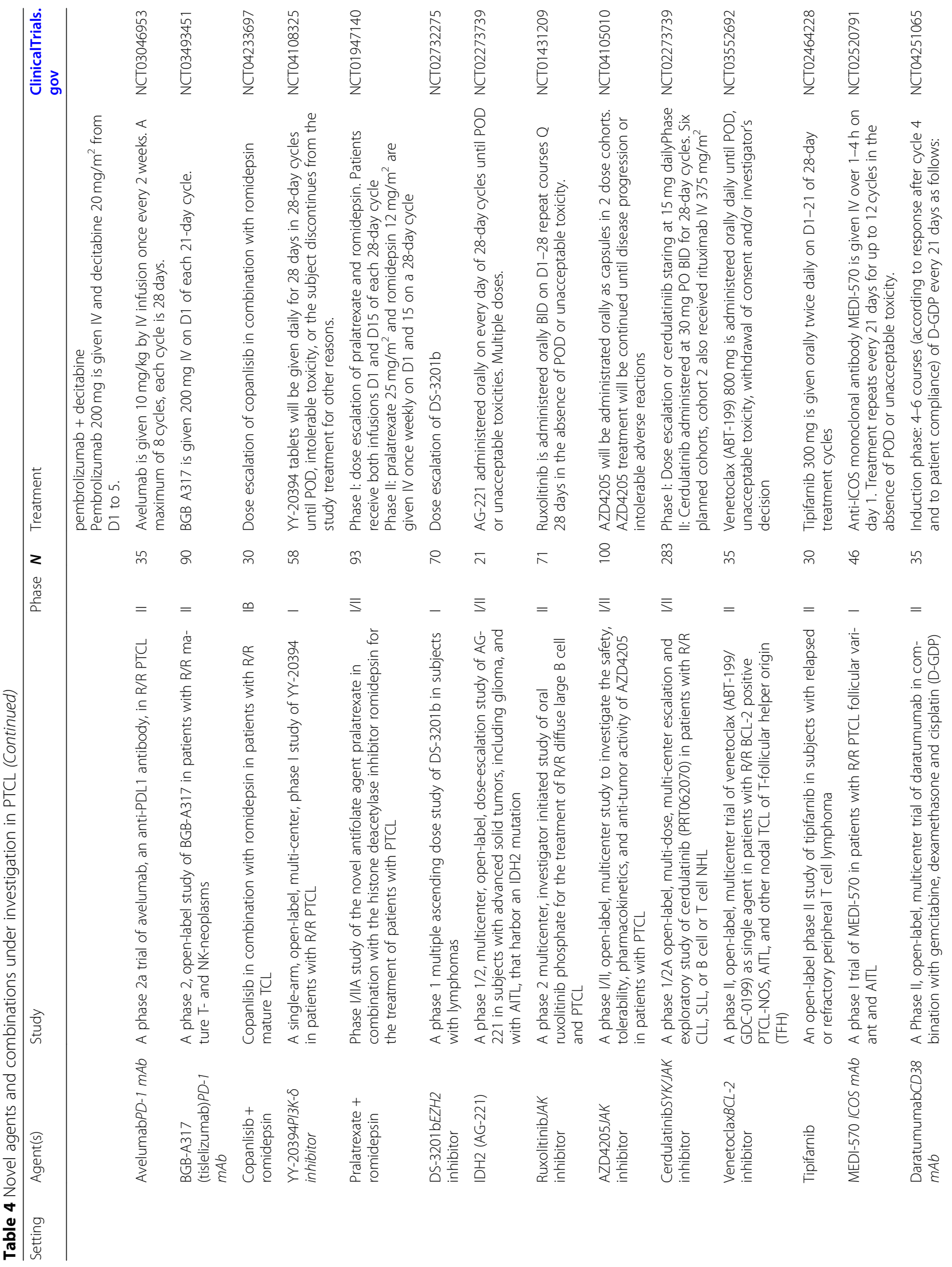




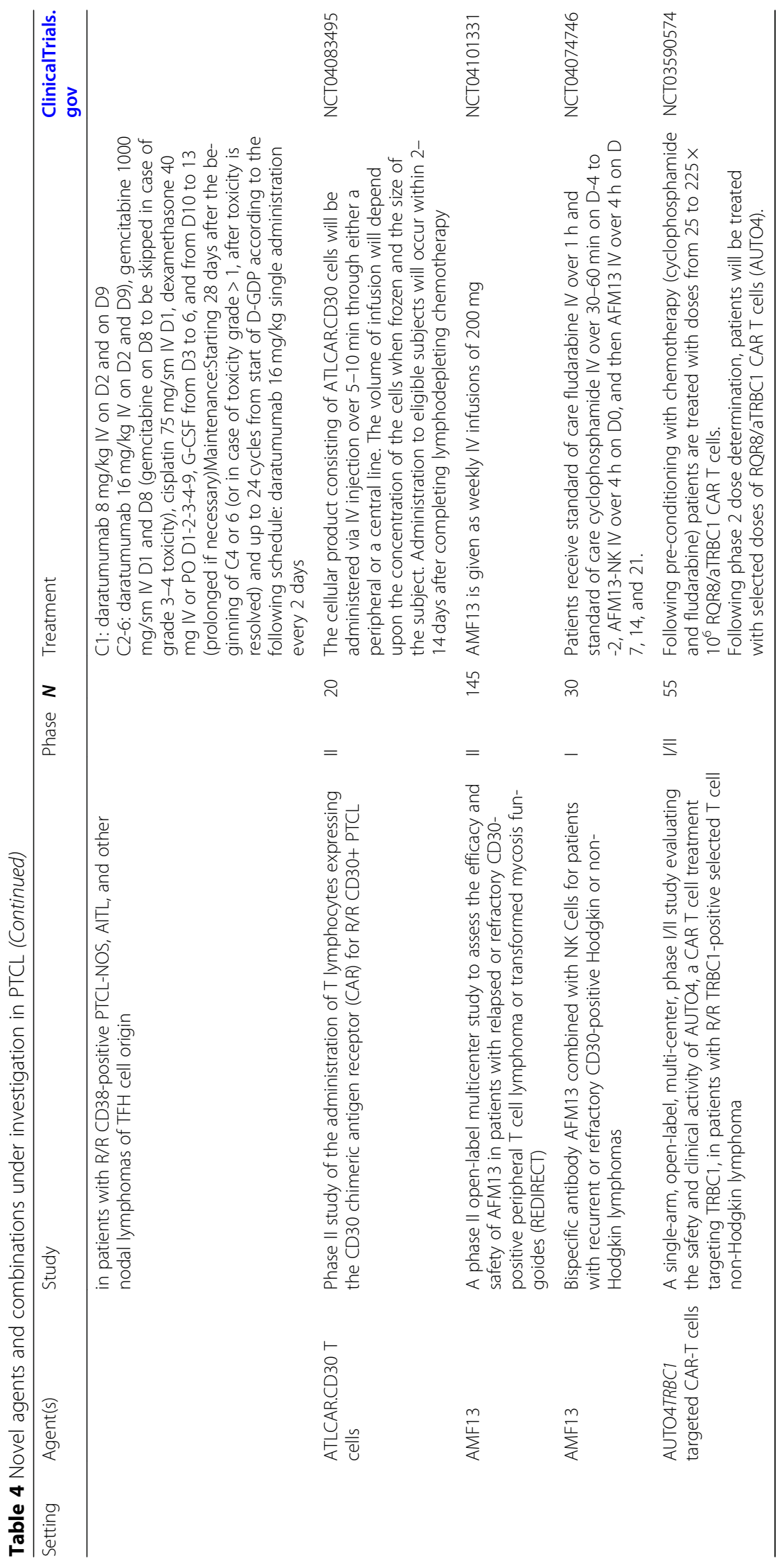


treatment with chidamide on days $1,4,8$, and 11 every 21 days for 24 months maximum. Overall, 46.6\% achieved $\mathrm{CR} / \mathrm{Cru}$ with an additional $35.7 \%$ of patients achieving a PR, and PFS and OS at 12 months were $54.3 \%$ and $100 \%$, respectively. Fifteen patients entered the consolidation phase. The combination was well tolerated with no AEs leading to discontinuation.

Hypomethylating agents In the frontline setting, a phase 2 multi-center trial evaluating the combination of oral azacitidine (CC486) plus $\mathrm{CHOP}$ as initial therapy for PTCL is ongoing, which prioritizes enrollment of PTCL patients with $\mathrm{T}$ follicular helper (TFH) phenotype and acquired genetic predisposition to chemosensitization by hypomethylating agent (NCT03542266). Treatment program consists of priming of oral azacitidine for 7-14 days prior to each cycle of standard CHOP.

\section{Targeting tumor microenvironment}

Lenalidomide in combination with CHOP-based chemotherapy was evaluated in 2 prospective phase 2 studies; both showed unexpectedly modest CR and PFS rates and high discontinuation rates due to substantial toxicities. The $\mathrm{T}$ cell Consortium study combined lenalidomide given $10 \mathrm{mg}$ on days 1-10 with standard-dose CHOEP (cyclophosphamide, doxorubicin, etoposide, vincristine, and prednisone) every 21-day cycle for 6 cycles followed by either upfront ASCT or lenalidomide maintenance (NCT02561273). The phase 2 efficacy analysis showed ITT ORR of $68 \%$ with CR of $48 \%$ and 1-year PFS and OS at $68 \%$ and $89 \%$, respectively. Serious AEs (SAEs) and AEs included 5 treatment-related deaths and significant grade $\geq 3$ cytopenias [76]. Lenalidomide ( 25 $\mathrm{mg} /$ day on days 1-14) plus CHOP was studied in AITL elderly patients by the French LYSA group (NCT01553 786) [77]. ITT CR in the Len-CHOP study was $43.6 \%$, with a 2-year PFS rate of $42.3 \%$ and a 2 -year OS of $60.1 \%$. Discontinuation rate was high at $28 \%$ due to toxicities and disease progression. Mutational analysis demonstrated TET2 mutations in 49 cases (77\%), RHOA ${ }^{\text {G17V }}$ mutations in 34 patients (53\%), DNMT3A mutations in 20 (31\%) patients, and IDH2 mutations in $14(22 \%)$.

\section{Antifolate combination}

The antifolate agent pralatrexate was incorporated into the front-line setting alternating with CEOP (cyclophosphamide, doxorubicin, vincristine, and prednisone) in a phase II T cell Consortium trial [78]. Of 33 patients, 21 had PTCL-not otherwise specified (64\%), 8 had AITL (24\%), and 4 had ALCL (12\%). Fifty-two percent of patients achieved a CR. The 2-year PFS and OS were 39\% and $60 \%$, respectively. Overall, this approach did not improve outcomes compared to historical data using CHOP.

\section{Novel combination free of conventional chemotherapy}

Given the efficacy of single-agent immunomodulatory agent lenalidomide and HDAC inhibitor romidepsin in PTCL, the combination of immunomodulation and epigenetic manipulation has the potential synergy to target both tumor microenvironment and tumor cells. Based on a phase I/II trial evaluating the combination of lenalidomide and romidepsin at the MTD of romidepsin 14 $\mathrm{mg} / \mathrm{m}^{2}$ IV on days 1,8 , and 15 and lenalidomide $25 \mathrm{mg}$ oral on days $1-21$ of a 28 -day cycle, which demonstrated ORR of $50 \%$ with acceptable safety profile in R/R PTCL [32], a multi-center phase 2 study is ongoing to assess the efficacy and safety of the romidepsin and lenalidomide combination in previously untreated PTCL patients who are not chemotherapy candidates (NCT02232516). Treatment is planned for up to 1 year in the absence of disease progression or unacceptable toxicities.

\section{Biomarker-driven consolidation and maintenance}

High-dose chemotherapy and autologous stem cell transplant (HDT-ASCT) for chemotherapy-sensitive disease is a therapeutic strategy for PTCL patients in first remission based on phase 2 studies. Three-year PFS with CHOPbased induction followed by HDT-ASCT was reported in the range of $36-44 \%$ in prospective studies $[79,80]$ and $58 \%$ in retrospective series $[81,82]$, signaling ongoing unmet needs for PFS improvement. Romidepsin maintenance therapy is being evaluated in a multi-center phase 2 study for patients in CR1/PR1 who have completed CHOP-based chemotherapy induction followed by HDTASCT with BEAM conditioning (NCT01908777). The primary objective is to assess 2-year PFS. The T cell Consortium frontline study with lenalidomide plus CHOEP has a built-in design of consolidation with either upfront ASCT or lenalidomide maintenance (NCT02561273). Of the responding patients $(68 \% ; n=30), 10$ proceeded to lenalidomide maintenance. The 1-year estimated PFS and OS are $68 \%$ and $89 \%$, respectively, and longer follow-up is needed to assess durability of lenalidomide maintenance treatment [76]. Maintenance strategy without HDT-ASCT was explored in the phase 1 frontline treatment of brentuximab vedotin (BV) plus CHOP combination. Patients received single-agent $\mathrm{BV}$ maintenance for $8-10$ cycles following CHOP chemotherapy [68]. In the 26 patients (19 ALCL) treated with BV + CHP combination therapy and BV maintenance, ORR was $100 \%$ with CR of $92 \%$, and 5year PFS and OS were $52 \%$ and $80 \%$, respectively, demonstrating durable remissions [69]. Ultimately, measurable improvement with consolidation and maintenance therapy will require confirmation from prospectively designed, randomized phase 3 studies. 


\section{Future directions}

Emerging novel agents and combinations are in active clinical development which target the epigenome, proliferative signaling pathways, and the tumor microenvironment. Given the frequency of alterations in histone methylation and acetylation genes in PTCL, EZH2, which encodes the histone-lysine $\mathrm{N}$-methyltransferase enzyme, has emerged as a potential therapeutic target. The EZH1/2 inhibitor DS-3201b has demonstrated in vitro anti-tumor activity in lymphoma cell lines and is being investigated in a phase I trial of patients with $R / R$ PTCL (NCT02732275). The IDH2 inhibitor AG-221 is being studied in patients with advanced solid tumors or gliomas or $\mathrm{R} / \mathrm{R}$ AITL who harbor these mutations (NCT02273739). An ongoing phase II trial is being conducted to explore the efficacy of the JAK $1 / 2$ inhibitor ruxolitinib in patients with $R / R$ lymphoma, including PTCL (NCT01431209). Alternative JAK inhibitors are also being investigated including AZD4205 (NCT04105010). The dual SYK/JAK inhibitor cerdulatinib is under evaluation in a phase I/II trial in patients with R/R CLL or NHL, including PTCL (NCT01994382). The BCL-2 inhibitor venetoclax has been approved for use in B cell lymphoma such as CLL and is now being investigated in an ongoing phase II trial in patients with BCL-2-positive TCL, including AITL and TFH origin PTCL (NCT03552692). Tipifarnib, a potent and selective inhibitor of farnesyltransferase, has been shown to modulate CXCL12 signaling pathway and has demonstrated promising preliminary results in patients with R/R AITL and CXCL12+ PTCL with ORR of $45 \%$ and a $73 \%$ clinical benefit rate [83] in a phase II trial in patients with R/R PTCL (NCT02464228). Engaging the tumor microenvironment remains an attractive approach in PTCL, and various novel strategies are under investigation. ICOS, an important member of the CD28/CTLA-4 family found on TFH cells, is being targeted with the monoclonal antibody MEDI-570 in an ongoing phase I trial in patients with PTCL follicular variant and AITL (NCT02520791). CD38 expression has been demonstrated in up to half of ENKTL [84], and the CD38 monoclonal antibody daratumumab has shown promising ORR of $35.7 \%$ in this population [85]. Daratumubab is being combined with gemcitabine, dexamethasone, and cisplatin in patients with CD38-positive PTCL (NCT04251065).

Several innovative techniques are being explored in PTCL. Chimeric antigen receptor $\mathrm{T}$ (CAR-T) cells directed against CD30 have been developed and are being explored in a phase II trial (NCT04083495) in patients with R/R CD30+ PTCL. AMF13, a bispecific antibody containing a binding site for CD30 and a second binding site for CD16A, the receptor responsible for NK cell activation, is being evaluated in R/
$\mathrm{R}$ CTCL (NCT04101331). This molecule is also under clinical investigation in combination with NK cells in patients with $\mathrm{R} / \mathrm{R} \mathrm{CD} 30+$ lymphomas (NCT04074746). The $\mathrm{T}$ cell receptor $\beta$-chain (TCRB) is a pan- $T$ cell antigen highly expressed on PTCL. CAR-T cells targeting TRBC1 are being studied in patients with TRBC1+ selected R/R PTCL (NCT03590574).

\section{Conclusion}

Peripheral $\mathrm{T}$ cell lymphomas are heterogeneous diseases, where relapse and refractory diseases are common. Recent advances in molecular and genomic profiling have provided unprecedented insight into disease pathogenesis driven by distinct cells of origins and molecular pathways. Delivering the most effective treatment tailored to underlying biology and therapeutic targets in the first-line and relapsed settings is poised to make the most enduring impact on patient's survival outcome.

\section{Abbreviations}

AE: Adverse event; AITL: Angioimmunoblastic T cell lymphoma; ALK: Anaplastic lymphoma kinase; ATLL: Adult T cell leukemia/lymphoma; AZA: Azacitadine; BV: Brentuximab-vedotin; CAR-T: Chimeric antigen receptor T cell; CEOP: Cyclophosphamide, etoposide, vincristine, prednisone; CHOEP: Cyclophosphamide, doxorubicin, etoposide, vincristine, and prednisone; CHOP: Cyclophosphamide, doxorubicin, vincristine, prednisone; CMV: Cytomegalovirus; CR: Complete response; CRu: Complete response unconfirmed; CTCL: Cutaneous T cell lymphoma; DOR: Duration of response; EATL: Enteropathy-associated T cell lymphoma; EBV: Epstein-Barr virus;

EFS: Event-free survival; ENKTL: Extranodal NKTT cell lymphoma; FTCL: Follicular T cell lymphoma; GEP: Gene expression profile; HDAC: Histone deacetylase; HSTL: Hepatosplenic T cell lymphoma; HTLV1: Human T cell leukemia virus, type 1; MF: Mycosis fungoides; NGS: Nextgeneration sequencing; ORR: Overall response rate; OS: Overall survival; PFS: Progression-free survival; PI3K: Phosphoinositide 3-kinase; PJP: Pneumocystis jiroveci pneumonia; PR: Partial response; PTCL: Peripheral T cell lymphoma; PTCL-NOS: Peripheral T cell lymphoma, not otherwise specified; R/R: Relapsed/refractory; sAE: Serious adverse event;

SALCL: Systemic anaplastic large cell lymphoma; SPTL: Subcutaneous panniculitis-like T cell lymphoma; TFH: T follicular helper

\section{Acknowledgements}

None

\section{Authors' contributions}

The authors each contributed to the concept design, data collection, and manuscript writing. EM created the figure. The authors read and approved the final manuscript.

\section{Funding}

Not applicable for this review.

Availability of data and materials

Not applicable for this review.

Ethics approval and consent to participate

Not applicable for this review.

Consent for publication

Not applicable for this review.

Competing interests

The authors have no competing interests to declare. 
Received: 12 March 2020 Accepted: 1 May 2020 Published online: 24 May 2020

\section{References}

1. AJ VJ, Weisenburger D. International T-Cell Lymphoma Project: International peripheral T-cell and natural killer/T-cell lymphoma study: pathology findings and clinical outcomes. Journal of Clinical Oncology. 2008;26:412430 .

2. Swerdlow SH, Campo E, Pileri SA, et al. The 2016 revision of the World Health Organization classification of lymphoid neoplasms. Blood. 2016;127: 2375-90.

3. Iqbal J, Wright G, Wang C, et al. Gene expression signatures delineate biological and prognostic subgroups in peripheral T-cell lymphoma. Blood. 2014;123:2915-23.

4. Wang T, Feldman AL, Wada DA, et al. GATA-3 expression identifies a highrisk subset of PTCL. NOS with distinct molecular and clinical features. Blood. 2014;123:3007-15.

5. Savage KJ, Harris NL, Vose JM, et al. ALK- anaplastic large-cell lymphoma is clinically and immunophenotypically different from both ALK+ ALCL and peripheral T-cell lymphoma, not otherwise specified: report from the International Peripheral T-Cell Lymphoma Project. Blood. 2008;111:5496-504.

6. Parrilla Castellar ER, Jaffe ES, Said JW, et al. ALK-negative anaplastic large cell lymphoma is a genetically heterogeneous disease with widely disparate clinical outcomes. Blood. 2014:124:1473-80.

7. Lunning MA, Vose JM. Angioimmunoblastic T-cell lymphoma: the manyfaced lymphoma. Blood. 2017:129:1095-102.

8. de Leval L, Rickman DS, Thielen C, et al. The gene expression profile of nodal peripheral T-cell lymphoma demonstrates a molecular link between angioimmunoblastic T-cell lymphoma (AITL) and follicular helper T (T< sub> $\mathrm{FH}</$ sub $>$ ) cells. Blood. 2007;109:4952-63.

9. de Leval L, Gaulard P. Cellular origin of T-cell lymphomas. Blood. 2014;123: 2909-10.

10. W-y A, Weisenburger DD. Intragumtornchai T, et al: Clinical differences between nasal and extranasal natural killer/T-cell lymphoma: a study of 136 cases from the International Peripheral T-Cell Lymphoma Project. Blood. 2009;113:3931-7.

11. Cook LB, Fuji S, Hermine O, et al. Revised adult T-cell leukemia-lymphoma international consensus meeting report. J Clin Oncol. 2019;37:677-87.

12. Kataoka K, Nagata $Y$, Kitanaka A, et al. Integrated molecular analysis of adult T cell leukemia/lymphoma. Nat Genet. 2015;47:1304-15.

13. Dürkop $H$, Latza $U$, Hummel $M$, et al. Molecular cloning and expression of a new member of the nerve growth factor receptor family that is characteristic for Hodgkin's disease. Cell. 1992;68:421-7.

14. Francisco JA, Cerveny CG, Meyer DL, et al. CAC10-vcMMAE, an anti-CD30monomethyl auristatin $\mathrm{E}$ conjugate with potent and selective antitumor activity. Blood. 2003;102:1458-65.

15. Pro B, Advani R, Brice $P$, et al. Brentuximab vedotin (SGN-35) in patients with relapsed or refractory systemic anaplastic large-cell lymphoma: results of a phase II study. Journal of Clinical Oncology. 2012;30:2190-6.

16. Horwitz SM, Advani RH, Bartlett NL, et al. Objective responses in relapsed Tcell lymphomas with single-agent brentuximab vedotin. Blood. 2014;123: 3095-100.

17. Xia MQ, Hale G, Lifely MR, et al. Structure of the CAMPATH-1 antigen, a glycosylphosphatidylinositol-anchored glycoprotein which is an exceptionally good target for complement lysis. Biochemical Journal. 1993; 293:633-40.

18. Jiang L, Yuan CM, Hubacheck J, et al. Variable CD52 expression in mature T cell and NK cell malignancies: implications for alemtuzumab therapy. British Journal of Haematology. 2009;145:173-9.

19. Geissinger E, Bonzheim I, Roth $\mathrm{S}$, et al. CD52 expression in peripheral T-cell lymphomas determined by combined immunophenotyping using tumor cell specific T-cell receptor antibodies. Leukemia \& Lymphoma. 2009;50: 1010-6.

20. Enblad G, Hagberg H, Erlanson M, et al. A pilot study of alemtuzumab (antiCD52 monoclonal antibody) therapy for patients with relapsed or chemotherapy-refractory peripheral T-cell lymphomas. Blood. 2004;103: 2920-4

21. Dearden C. Management of prolymphocytic leukemia. Hematology Am Soc Hematol Educ Program. 2015:2015:361-7.

22. Dearden C. How I treat prolymphocytic leukemia. Blood. 2012;120:538-51.
23. Dearden CE, Khot A, Else M, Hamblin M, Grand E, Roy A, Hewamana S,

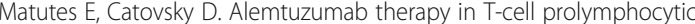
leukemia: comparing efficacy in a series treated intravenously and a study piloting the subcutaneous route. Blood. 2011;118(22):5799-802. 10.1182/ blood-2011-08-372854

24. Wilcox RA. Mogamulizumab: 2 birds, 1 stone. Blood. 2015;125:1847-8.

25. Ishida T, Inagaki H, Utsunomiya A, et al. CXC chemokine receptor 3 and CC chemokine receptor 4 expression in T-cell and NK-cell lymphomas with special reference to clinicopathological significance for peripheral T-cell lymphoma, unspecified. Clinical Cancer Research. 2004;10:5494-500.

26. Ishida T, Joh T, Uike N, et al. Defucosylated anti-CCR4 monoclonal antibody (KW-0761) for relapsed adult T-cell leukemia-lymphoma: a multicenter phase II study. Journal of Clinical Oncology. 2012;30:837-42.

27. Ishida T, Utsunomiya A, Jo T, et al. Mogamulizumab for relapsed adult T-cell leukemia-lymphoma: Updated follow-up analysis of phase I and II studies. Cancer Sci. 2017;108(10):2022-9. https://doi.org/10.1111/cas.13343.

28. Piekarz RL, Robey RW, Zhan Z, et al. T-cell lymphoma as a model for the use of histone deacetylase inhibitors in cancer therapy: impact of depsipeptide on molecular markers, therapeutic targets, and mechanisms of resistance. Blood. 2004;103:4636-43.

29. Olsen EA, Kim YH, Kuzel TM, et al. Phase Illb multicenter trial of vorinostat in patients with persistent, progressive, or treatment refractory cutaneous Tcell lymphoma. J Clin Oncol. 2007;25:3109-15.

30. Coiffier B, Pro B, Prince HM, et al. Results from a pivotal, open-label, phase II study of romidepsin in relapsed or refractory peripheral T-cell lymphoma after prior systemic therapy. Journal of Clinical Oncology. 2012;30:631-6.

31. Coiffier B, Pro B, Prince HM, et al. Romidepsin for the treatment of relapsed/ refractory peripheral T-cell lymphoma: pivotal study update demonstrates durable responses. Journal of Hematology \& Oncology. 2014;7:11.

32. Mehta-Shah N, Lunning MA, Boruchov AM, et al. A phase $1 / \|$ trial of the combination of romidepsin and lenalidomide in patients with relapsed/ refractory lymphoma and myeloma: activity in T-cell lymphoma. Journal of Clinical Oncology. 2015;33:8521-1.

33. Mehta-Shah N, Moskowitz AJ, Lunning MA, et al. A phase $\mathrm{lb} / \mathrm{lla}$ trial of the combination of romidepsin, lenalidomide and carfilzomib in patients with relapsed/refractory lymphoma shows complete responses in relapsed and refractory B- and T-cell lymphomas. Blood. 2017;130:821-1.

34. Amengual JE, Lichtenstein $\mathrm{R}$, Lue J, et al. A phase 1 study of romidepsin and pralatrexate reveals marked activity in relapsed and refractory T-cell lymphoma. Blood. 2018;131:397-407.

35. O'Connor OA, Horwitz S, Masszi T, et al. Belinostat in patients with relapsed or refractory peripheral T-cell lymphoma: results of the pivotal phase II BELIEF (CLN-19) study. Journal of Clinical Oncology. 2015;33:2492-9.

36. Shi $Y$, Dong $M$, Hong $X$, et al. Results from a multicenter, open-label, pivotal phase II study of chidamide in relapsed or refractory peripheral T-cell lymphoma. Ann Oncol. 2015;26:1766-71.

37. Shih AH, Abdel-Wahab O, Patel JP, et al. The role of mutations in epigenetic regulators in myeloid malignancies. Nature Reviews Cancer. 2012;12:599.

38. Lemonnier F, Dupuis J, Sujobert $P$, et al: Treatment with 5-azacytidine induces a sustained response in patients with angioimmunoblastic T-cell lymphoma. Blood:blood-2018-04-840538, 2018.

39. O'Connor OA, Falchi L, Lue JK, et al. Oral 5-azacytidine and romidepsin exhibit marked activity in patients with PTCL: a multicenter phase 1 study. Blood. 2019;134:1395-405.

40. Ishida Y, Agata Y, Shibahara K, et al. Induced expression of PD-1, a novel member of the immunoglobulin gene superfamily, upon programmed cell death. The EMBO journal. 1992;11:3887-95.

41. Krishnan C, Warnke RA, Arber DA, et al. PD-1 expression in T-cell lymphomas and reactive lymphoid entities: potential overlap in staining patterns between lymphoma and viral lymphadenitis. The American Journal of Surgical Pathology. 2010;34:178-89.

42. Dupuis J, Boye K, Martin N, et al. Expression of CXCL13 by neoplastic cells in angioimmunoblastic T-cell lymphoma (AITL): a new diagnostic marker providing evidence that AITL derives from follicular helper T cells. The American Journal of Surgical Pathology. 2006;30:490-4.

43. Hsi ED, Said J, Macon WR, et al. Diagnostic accuracy of a defined immunophenotypic and molecular genetic approach for peripheral T/NKcell lymphomas: a North American PTCL study group project. The American Journal of Surgical Pathology. 2014;38:768-75. 
44. Jo JC, Kim M, Choi Y, et al. Expression of programmed cell death 1 and programmed cell death ligand 1 in extranodal NK/T-cell lymphoma, nasal type. Annals of Hematology. 2017;96:25-31.

45. Kataoka K, Iwanaga M. Yasunaga J-i, et al: Prognostic relevance of integrated genetic profiling in adult T-cell leukemia/lymphoma. Blood. 2018;131:21525.

46. Wartewig T, Kurgyis Z, Keppler S, et al. PD-1 is a haploinsufficient suppressor of T cell lymphomagenesis. Nature. 2017:552:121.

47. Ratner $L$, Waldmann TA, Janakiram $M$, et al. Rapid progression of adult T-cell leukemia-lymphoma after PD-1 inhibitor therapy. New England Journal of Medicine. 2018;378:1947-8.

48. Lesokhin AM, Ansell SM, Armand P, et al. Nivolumab in patients with relapsed or refractory hematologic malignancy: preliminary results of a phase Ib study. Journal of Clinical Oncology. 2016;34:2698-704.

49. Barta SK, Zain J, MacFarlane AW, et al: Phase II study of the PD-1 inhibitor pembrolizumab for the treatment of relapsed or refractory mature T-cell lymphoma. Clin Lymphoma Myeloma Leuk 19:356-364.e3, 2019.

50. Morschhauser F, Fitoussi $O$, Haioun $C$, et al. A phase 2, multicentre, singlearm, open-label study to evaluate the safety and efficacy of single-agent lenalidomide (Revlimid ${ }^{\circledR}$ ) in subjects with relapsed or refractory peripheral Tcell non-Hodgkin lymphoma: the EXPECT trial. European Journal of Cancer. 2013;49:2869-76.

51. Ishida T, Fujiwara H, Nosaka K, et al. Multicenter phase II study of lenalidomide in relapsed or recurrent adult T-cell leukemia/lymphoma: ATLL-002. Journal of Clinical Oncology. 2016;34:4086-93.

52. Mossé YP, Voss SD, Lim MS, et al. Targeting ALK with crizotinib in pediatric anaplastic large cell lymphoma and inflammatory myofibroblastic tumor: a children's oncology group study. Journal of Clinical Oncology. 2017;35:3215-21.

53. Gambacorti Passerini C, Farina F, Stasia A, et al: Crizotinib in advanced, chemoresistant anaplastic lymphoma kinase-positive lymphoma patients. J Natl Cancer Inst 106:djt378, 2014.

54. Clayton E, Bardi G, Bell SE, et al. A crucial role for the p110delta subunit of phosphatidylinositol 3-kinase in B cell development and activation. J Exp Med. 2002;196:753-63.

55. Vanhaesebroeck B, Guillermet-Guibert J, Graupera M, et al. The emerging mechanisms of isoform-specific PI3K signalling. Nat Rev Mol Cell Biol. 2010;11:329_ 41.

56. Horwitz SM, Koch R, Porcu P, et al: Activity of the PI3K-delta,gamma inhibitor duvelisib in a phase 1 trial and preclinical models of T-cell lymphoma. Blood 131:888-898, 2018.

57. Horwitz SM, Moskowitz AJ, Jacobsen ED, et al: The combination of duvelisib, a PI3K- $\delta, y$ inhibitor, and romidepsin is highly active in relapsed/refractory peripheral T-cell lymphoma with low rates of transaminitis: results of parallel multicenter, phase 1 combination studies with expansion cohorts. Blood 132:683-683, 2018

58. Witzig TE, Reeder C, Han JJ, et al. The mTORC1 inhibitor everolimus has antitumor activity in vitro and produces tumor responses in patients with relapsed T-cell lymphoma. Blood. 2015;126:328-35.

59. Tomita M, Toyota M, Ishikawa C, et al. Overexpression of Aurora A by loss of CHFR gene expression increases the growth and survival of HTLV-1-infected T cells through enhanced NF-kappaB activity. Int J Cancer. 2009:124:2607-15.

60. Evans R, Naber C, Steffler T, et al. Aurora A kinase RNAi and small molecule inhibition of Aurora kinases with VE-465 induce apoptotic death in multiple myeloma cells. Leuk Lymphoma. 2008:49:559-69.

61. Ye D, Garcia-Manero G, Kantariian HM, et al. Analysis of Aurora kinase A expression in CD34(+) blast cells isolated from patients with myelodysplastic syndromes and acute myeloid leukemia. J Hematop. 2009:2:2-8.

62. Barr PM, Li H, Spier C, et al. Phase II intergroup trial of alisertib in relapsed and refractory peripheral T-cell lymphoma and transformed mycosis fungoides: SWOG 1108. J Clin Oncol. 2015;33:2399-404.

63. O'Connor OA, Ozcan M, Jacobsen ED, et al. Randomized phase III study of alisertib or investigator's choice (selected single agent) in patients with relapsed or refractory peripheral T-cell lymphoma. J Clin Oncol. 2019;37:613-23.

64. Zullo KM, Guo Y, Cooke L, et al. Aurora A kinase inhibition selectively synergizes with histone deacetylase inhibitor through cytokinesis failure in T-cell lymphoma. Clin Cancer Res. 2015:21:4097-109.

65. Strati $P$, Nastoupil $L$, Davis RE, et al. A phase 1 trial of alisertib and romidepsin for relapsed/refractory aggressive B-cell and T-cell lymphomas. Haematologica. 2020;105:e26-8.
66. O'Connor OA, Pro B, Pinter-Brown $L$, et al. Pralatrexate in patients with relapsed or refractory peripheral T-cell lymphoma: results from the pivotal PROPEL study. J Clin Oncol. 2011;29:1182-9.

67. Schmitz N, Trümper L, Ziepert M, et al. Treatment and prognosis of mature T-cell and NK-cell lymphoma: an analysis of patients with T-cell lymphoma treated in studies of the German High-Grade Non-Hodgkin Lymphoma Study Group. Blood. 2010;116:3418-25.

68. Fanale MA, Horwitz SM, Forero-Torres A, et al. Brentuximab vedotin in the front-line treatment of patients with CD30+ peripheral T-cell lymphomas: results of a phase I study. Journal of Clinical Oncology. 2014;32:3137-43.

69. Fanale MA, Horwitz SM, Forero-Torres A, et al. Five-year outcomes for frontline brentuximab vedotin with CHP for CD30-expressing peripheral Tcell lymphomas. Blood. 2018;131:2120-4.

70. Horwitz S, O'Connor OA, Pro B, et al. Brentuximab vedotin with chemotherapy for CD30-positive peripheral T-cell lymphoma (ECHELON-2): a global, double-blind, randomised, phase 3 trial. The Lancet. 2019;393:229-40.

71. Gallamini A, Zaja F, Patti C, et al. Alemtuzumab (Campath-1H) and CHOP chemotherapy as first-line treatment of peripheral T-cell Iymphoma: results of a GITIL (Gruppo Italiano Terapie Innovative nei Linfomi) prospective multicenter trial. Blood. 2007:110:2316-23.

72. van Imhoff GW, Kluin-Nelemans HC, van Marwijk KM, et al. Intensified alemtuzumab-CHOP therapy for peripheral T-cell lymphoma. Annals of Oncology. 2011;22:1595-600.

73. Roswarski J, Roschewski M, Melani C, et al: Phase 1/2 study of alemtuzumab with dose-adjusted $\mathrm{EPOCH}$ in untreated aggressive $\mathrm{T}$ and NK cell lymphomas. Leukemia \& Lymphoma:1-5, 2019.

74. Johnston PB, Cashen AF, Nikolinakos PG, et al. Safe and effective treatment of patients with peripheral T-cell lymphoma (PTCL) with the novel HDAC inhibitor, belinostat, in combination with CHOP: results of the Bel-CHOP phase 1 trial. Blood. 2015;126:253-3.

75. Shi Y, Gui L, Cao J, et al. A phase $1 \mathrm{~b} / 2$ study of chidamide combined with CHOP in previously untreated patients with peripheral T-cell lymphoma (PTCL). Blood. 2019;134:2840-0.

76. Lunning MA, Horwitz SM, Advani R, et al. Phase I/II study of CHOEP plus lenalidomide as initial therapy for patients with stage II-IV peripheral T-cell lymphoma: phase II results. Blood. 2018;132:2899-9.

77. Lemonnier F, Safar V, de Leval L, et al. Lenalidomide in combination with CHOP in patients with angioimmunoblastic T-cell lymphoma (AITL): final analysis of clinical and molecular data of a phase 2 Lysa study. Blood. 2018;132:999-9.

78. Advani RH, Ansell SM, Lechowicz MJ, et al. A phase II study of cyclophosphamide, etoposide, vincristine and prednisone (CEOP) alternating with pralatrexate $(P)$ as front line therapy for patients with peripheral T-cell lymphoma (PTCL): final results from the T-cell consortium trial. Br J Haematol. 2016;172:535-44.

79. Reimer $P$, Rüdiger T, Geissinger $E$, et al. Autologous stem-cell transplantation as first-line therapy in peripheral T-cell lymphomas: results of a prospective multicenter study. Journal of Clinical Oncology. 2009;27:106-13.

80. d'Amore F, Relander T, Lauritzsen GF, et al. Up-front autologous stemcell transplantation in peripheral T-cell lymphoma: NLG-T-01. Journal of Clinical Oncology. 2012;30:3093-9.

81. Smith SM, Burns LJ. Besien Kv, et al: Hematopoietic cell transplantation for systemic mature T-cell non-Hodgkin lymphoma. Journal of Clinical Oncology. 2013:31:3100-9.

82. Abramson JS, Evens AM, Goy A, et al. Peripheral T-cell lymphomas in a large US multicenter cohort: prognostication in the modern era including impact of frontline therapy. Annals of Oncology. 2014;25:2211-7.

83. Witzig $T$, Sokol L, Kim W. Tipifarnib in relapsed or refractory angioimmunoblastic T-cell lymphoma (AITL) and CXCL12+ periphera T-cell lymphoma (PTCL): preliminary results from a phase 2 study; 2020

84. Wang L, Wang H, Li PF, et al. CD38 expression predicts poor prognosis and might be a potential therapy target in extranodal NK/T cell lymphoma, nasal type. Ann Hematol. 2015;94:1381-8.

85. Kim W-S. Daratumumab monotherapy for patients with relapsed or refractory ( $R$ ) R) natural killer/T-cell lymphoma (NKTCL), nasal type: an open-label, single-arm, multicenter phase 2 study | Blood | American Society of Hematology; 2020

86. Ogura M, Ishida T, Hatake K, et al. Multicenter phase II study of mogamulizumab (KW-0761), a defucosylated anti-cc chemokine receptor 4 
antibody, in patients with relapsed peripheral T-cell lymphoma and cutaneous T-cell lymphoma. J Clin Oncol. 2014;32:1157-63.

87. O'Connor OA, Özcan M, Jacobsen ED, et al. First multicenter, randomized phase 3 study in patients (Pts) with relapsed/refractory (R/R) peripheral Tcell lymphoma (PTCL): alisertib (MLN8237) versus investigator's choice (Lumiere trial; NCT01482962). Blood. 2015;126:341-1.

88. Kwong Y-L, Chan TSY, Tan D, et al. PD1 blockade with pembrolizumab is highly effective in relapsed or refractory NK/T-cell lymphoma failing Lasparaginase. Blood. 2017;129:2437-42.

89. d'Amore F, Leppä S. Gomes da Silva M: Final analysis of the front-line phase III randomized ACT-1 trial in younger patients with systemic peripheral Tcell lymphoma treated with CHOP chemotherapy with or without alemtuzumab and consolidated by autologous hematopoietic stem cel transplant. Blood. 2018;132:998.

90. Dupuis J, Morschhauser F, Ghesquières $\mathrm{H}$, et al. Combination of romidepsin with cyclophosphamide, doxorubicin, vincristine, and prednisone in previously untreated patients with peripheral T-cell lymphoma: a nonrandomised, phase 1b/2 study. The Lancet Haematology. 2017;2:e160-5.

\section{Publisher's Note}

Springer Nature remains neutral with regard to jurisdictional claims in published maps and institutional affiliations.

Ready to submit your research? Choose BMC and benefit from:

- fast, convenient online submission

- thorough peer review by experienced researchers in your field

- rapid publication on acceptance

- support for research data, including large and complex data types

- gold Open Access which fosters wider collaboration and increased citations

- maximum visibility for your research: over $100 \mathrm{M}$ website views per year

At BMC, research is always in progress.

Learn more biomedcentral.com/submissions 